\title{
The Intergenerational Earnings and Income Mobility of Canadian Men: Evidence from Longitudinal Income Tax Data
}

by

\author{
Miles Corak* and Andrew Heisz**
}

No. 113

11F0019MPE No. 113

ISSN: 1200-5223

ISBN: 0-660-17611-4

Price: $\$ 5.00$ per issue, $\$ 25.00$ annually

Business and Labour Market Analysis

24 -H, R.H. Coats Building, Ottawa, K1A 0T6

*(613) 951-9047

**(613) 951-3748

Facsimile Number: (613) 951-5403

E-mail: coramil@statcan.ca

\section{October 1998}

An earlier version of this paper was circulated under the title "Unto the Sons: the Intergenerational Income Mobility of Canadian Men. Previous drafts were also presented to the meetings of the Society of Labor Economists, the European Society for Population Economics, the Canadian Economics Association, and to departmental seminars at Carleton University, Cornell University, the OECD, Statistics Canada, and Syracuse University. We would like to thank Martin Browning, Kenneth Couch, Stephen Jenkins, Stephen Jones, Dean Lillard, Harry Paarsch, James Pesando, Geoff Rowe, and Andreas Stich for their comments and suggestions. We would also like to thank Clive Loader for making the S-plus code used in the non-parametric analysis available to us, to acknowledge the help of Linda Standish and André St. Louis of Statistics Canada in constructing the data set, and to thank Sophie Lefebvre for her able research assistance.

This paper represents the views of the author and does not necessarily reflect the opinions of Statistics Canada. 


\section{Table of Contents}

I. Introduction _ 0

II. Methodology and Literature Survey ___ 1

III. Regression Results Using Linear Specifications ___ 3

IV. Representativeness and Accuracy of the Data _ 5

V. Non-Linearities _ 8

VI. Conclusion___ 11

Appendix__ 23

Bibliography _ 26 


\section{Abstract}

Our objective is to obtain an accurate estimate of the degree of intergenerational income mobility in Canada. We use income tax information on about 400,000 father-son pairs, and find intergenerational earnings elasticities to be about 0.2. Earnings mobility tends to be slightly greater than income mobility, but non-parametric techniques uncover significant non-linearities in both of these relationships. Intergenerational earnings mobility is greater at the lower end of the income distribution than at the upper end, and displays an inverted V-shape elsewhere. Intergenerational income mobility follows roughly the same pattern, but is much lower at the very top of the income distribution.

JEL Classification: D31, I132, J62

Keywords: Intergenerational Income Mobility, Income Distribution, Non-parametric regression 


\section{Introduction}

The objective of this paper is to examine the degree to which individuals "inherit" their economic status, that is the degree of intergenerational mobility. What is the extent of the economic advantage conferred to offspring of the rich? On the other hand, is poverty a state that is passed on to subsequent generations?

The growing literature devoted to the estimation of intergenerational income mobility in the OECD countries is for the most part based upon a linear regression model. The focus of attention has been on the potential biases associated with life-cycle differences between (most often) fathers and sons, and measurement error associated with transitory fluctuations in incomes or mistakes in reporting. In spite of the fact that some theories are specifically concerned with nonlinearities, and in spite of the fact that related empirical analyses based on transition matrices suggest they may be present in the data, the possibility that the linear model is mis-specified has not been addressed in any detail.

This is a major theme in our study. We focus on the relationship between the adult incomes of a cohort of Canadian men born between 1963 and 1966, and living in households with a father present. The analysis is based upon administrative data associated with the Canadian income tax. As a result our sample size is very large, close to 400,000 father-son pairs. The data have a number of strengths, and we try to play to these while at the same time working around any weaknesses. In particular, administrative data offer information not only on the amount of income, but also its composition. Accordingly we examine both intergenerational earnings mobility and income mobility. Further, the large sample size permits the use of non-parametric techniques to examine non-linearities in the degree of intergenerational mobility.

We begin by offering an overview of the existing literature, and then proceed in three steps. First, using our data we address concerns raised in the literature, namely potential biases originating in life-cycle differences between fathers and sons and measurement error associated with the derivation of permanent income. Second, we examine potential limitations of the data: the possibility of biases due to sample selection, and under-reporting of income. Finally we explore non-linear patterns by first examining quartile, decile, and percentile transition matrices, and then adopting non-parametric techniques, specifically a version of nearest-neighbourhood estimation.

Among our findings is the result that there is a good deal of intergenerational mobility among Canadian men. On average the intergenerational correlation of earnings and market incomes between fathers and sons is probably about 0.2 , a value that until recently was considered to be the consensus in the United States. Nonetheless, our use of non-parametric techniques uncovers significant non-linearities in this relationship. The degree of intergenerational earnings mobility is much greater at the lower end of the income distribution than at the upper end. The elasticity of father and son earnings is about 0.0 at the bottom percentile and rises to about 0.4 at the top percentile. However, it follows an inverted V-shape over intermediate parts of the distribution. Income mobility follows a roughly similar pattern, but is much lower at the very top of the distribution. The intergenerational elasticity between father and son incomes at the top percentile is almost 0.8 . 
Some of these patterns can be understood in the context of a borrowing constraints model. However, we stop short of interpreting them as the result of specific policy interventions, and suggest that in order to do so will require more research from other countries on the degree and pattern of non-linearities in intergenerational mobility.

\section{Methodology and Literature Survey}

The existing literature has examined intergenerational income mobility in two complementary ways: by least squares estimation of an autoregressive model linking a child's income (as an adult) to the parent's income, and by the construction of a transition matrix relating the child's position in the income distribution to the parent's position.

In the first case a child's income is expressed as a (linear) function of his or her parent's income. If $Y$ represents permanent income (generally measured in logarithms), $t$ the child's generation, and $t-1$ the parent's generation then the standard data generating process is assumed to be:

$$
Y_{i}(t)=\beta_{0}+\beta_{1} Y_{i}(t-1)+\varepsilon_{i}
$$

where the data are at the individual level, $i$ denotes a father-son pair, and $\varepsilon_{i}$ is a random component usually assumed to be distributed as $N\left(0, \sigma^{2}\right)$. The constant term represents the change in income common to generation $t$, while the coefficient $\beta_{1}$ indicates the extent to which income levels are related to those of the parent's, that is the extent of intergenerational mobility. ${ }^{1}$

An accurate estimate of $\beta_{1}$ is the main concern of studies that adopt this approach. If $\beta_{1}$ is less than one the income distribution is said to regress to the mean: while parents with incomes above (or below) the mean will have children with above (or below) average income levels miles the deviation from the mean will not be as great. This should not be too surprising in advanced industrialized societies. However, the larger $\beta_{1}$ (even if it is less than one) the more likely that an individual as an adult will inhabit the same economic position as his or her parents, that is the greater the persistence in intergenerational income levels. Even small values of $\beta_{1}$ confer substantial advantages to the children of the well off. ${ }^{2}$

Models like equation (1) have been estimated with data from a number of countries, but the research with U.S. data is the most extensive. Altonji and Dunn (1991), Behrman and Taubman (1990), Mulligan (1997), Peters (1992), Shea (1997), Solon (1992), and Zimmerman (1992) represent some recent examples, while earlier research covering several countries in addition to the U.S. is summarized in Becker and Tomes (1986). The latter suggest that a consensus value for $\beta_{1}$ seems to be 0.2 . These findings, however have been criticized as being biased because of measurement error and sample selection problems, which are discussed by Atkinson, Maynard, and Trinder (1983), Jenkins (1987), and Solon (1989,1992). Solon, for example, notes that ideally $Y_{i}(t)$ and $Y_{i}(t-1)$ in equation (1) should be measures of permanent income, but often researchers are forced to use a measure of income in a given year, say $\tilde{Y}_{i}(t-1)=Y_{i}(t-1)+v_{i}$, where $v_{i}$ represents a transitory shock to income. This results in an errors in variables problem leading the estimated coefficient $(\tilde{\beta})$ to differ from the true coefficient according to a factor determined by the ratio of the variance of $v_{i}$ to that of $Y_{i}$, so that $\tilde{\beta}\left(1+\sigma_{v}^{2} / \sigma_{Y}^{2}\right)=\beta_{1}$. Solon 
(1989) suggests that $\tilde{\beta}$ should be inflated by a factor of 1.3 to 1.8 when a representative sample is being used. He notes, however, that many studies are based upon samples that are overly homogenous so that the sample variance of $Y$ in effect understates the population variance, and thereby exacerbates the measurement error bias. The consensus estimate of 0.2 suggested by Becker and Tomes is based upon studies subject to these biases. Behrman and Taubman (1990), Lillard and Reville (1997), Mulligan (1997) and Solon (1992) correct for these problems and estimate $\beta_{1}$ to be about 0.4 to 0.5 , the former offering a preferred value as high as 0.6. Zimmerman (1992) also reports an estimate of 0.4, but Peters (1992) using the same data obtains estimates that vary between 0.1 and 0.2 as do Couch and Dunn (1997) who use the PSID.

The breadth of this literature is not as great as the number of studies would suggest. The data for all of the U.S. surveys is based on only two different surveys (either the Panel Study of Income Dynamics or the National Longitudinal Survey) and upon sample sizes that can be quite small. As an example, Solon (1992) uses a sample of 348 father-son pairs from the PSID, while Zimmerman (1992) uses 876 from the NLS. Some of the sample sizes in Cooper et al. (1993) are less than 100 observations. Couch and Dunne (1997) and Couch and Lillard (1997) point out that exclusion rules used in the construction of the sample for analysis may have an important influence on the estimates obtained. Given that most researchers are using the same data sets, the small sample size in the context of specification and measurement problems contributes to the diversity of estimates obtained.

Research from other countries is more limited, but growing. Atkinson, Maynard, and Trinder (1983) provide evidence based on data from a single British city that $\beta_{1}$ is about 0.4 to 0.45 depending upon the way income is measured, and Dearden, Machin, and Reed (1997) offer an estimate of about 0.4 to 0.6 using a more representative sample. Gustafsson (1994) and Björklund and Jäntti (1997a) studying Swedish data obtain an estimate of about 0.2 to 0.25. Björklund and Jäntti (1997b), Mulligan (1997, chapter 7), and Solon (1997) offer detailed surveys of the international evidence, but perhaps the most striking issue, from our perspective, is the dearth of Canadian evidence. To our knowledge the issue of intergenerational mobility has not received a great deal of attention by Canadian economists. ${ }^{3}$ In a preliminary version of our research (Corak and Heisz, 1995) we obtained an estimate of a little less than 0.2, but this study paid scant attention to measurement issues inherent in the data. Fortin and Lefebvre (1998) obtain a similar result using survey data.

The second approach to the study of intergenerational income mobility, the derivation of a transition matrix, is complementary to the use of autoregressive models. This approach involves dividing the population into equal sized groups ranked in order of income, and presenting the distribution of parents and children across these groups. The value of the transition matrix is that it offers a more detailed depiction of intergenerational mobility. Peters (1992) and Dearden, Machin and Reed (1997) present typical examples. In both studies about one third of sons born to fathers in the bottom quartile rose to the top half of the income distribution. They also find that there is less mobility at the top and bottom of the distribution, with sons born to fathers at the two extremes of the income distribution much more likely to occupy the same position as adults than sons born to fathers with incomes in the second and third quartiles. However, this may also illustrate a disadvantage. As Atkinson, Maynard, and Trinder (1983, p.83) point out, the non-linear pattern could in part reflect ceilings and floors at the top and bottom of the matrix: upward mobility is not possible for those born at the top, nor is downward mobility for those born at the bottom. As a result the degree of immobility at the top and bottom is exaggerated. 
The use of regression models is not subject to this limitation. Indeed, the possibility of nonlinearities has been noted by researchers estimating autoregressions. Solon (1992) augments equation (1) with the square of the father's income, but finds, in large part because of the small size of his sample, that it is not significant. Mulligan (1997, p.193) also finds no evidence of non-linearities, and suggests that this may be in part due to the fact that the PSID underrepresents individuals at the top of the income distribution. In contrast, Behrman and Taubman (1990) using the PSID, and Lillard (1998) and Peters (1992) using the NLSY find that higher order terms are statistically significant.

Non-linearities are an important element in theories of intergenerational income dynamics. The major contribution to this field is the work of Becker and Tomes $(1979,1986)$ and Becker (1991), as well as Bénabou (1994) and Durlauf (1994, 1996). Becker and Tomes (1986) model intergenerational mobility in the context of a human capital model reflecting the decisions of parents to consume their income or invest it in their children. They incorporate capital market constraints and thereby raise the possibility that the correlation between family income and the child's adult income may be greater among low income families than high income families. Mulligan (1997) offers a clear exposition of this model and its implications for non-linearities. Durlauf's rationale for persistent intergenerational poverty is based upon neighbourhood effects associated with the quality and financing of schooling. Some empirical work has incorporated insights drawn from these models to include additional variables in the estimation of equation (1) or to stratify samples in particular ways, but there does not appear to be a consensus in this literature on the nature and extent of non-linear patterns. ${ }^{4}$

\section{Regression Results Using Linear Specifications}

Solon (1992) and Zimmerman (1992) have paid the closest attention to the measurement and methodological issues that may bias estimates of equation (1). Their work is responsible for a reassessment of the degree of intergenerational mobility in the U.S. and suggests that there is considerably less mobility than previously thought. This is the starting point of our analysis.

In contrast to their work, and to much of the literature, we employ information drawn from income tax records. Our sample size is very large and not subject to problems of attrition or reporting errors. We examine a cohort of men aged 16 to 19 years of age in 1982 who filed an income tax return at some point between 1982 and 1986 (while still at home), and who had a "father" present during that year." The family linkages through the income tax records are produced as a part of the construction of the T1 Family File (T1FF) by Statistics Canada, which is described in the Appendix. Among other things the T1FF permits us to establish a link between the Social Insurance Numbers (SINs) of fathers and sons. Further by using the raw income tax files we are able to trace the incomes of the fathers back to 1978 (the first year in which the T1 information is available), and the incomes of sons forward to 1995, when they were 29 to 32 years of age. To remain in the sample the sons must have filed an income tax return in 1995. In addition, we follow Solon (1992) by using only the oldest sons when more than one son has been matched to the same father. The analysis is based on earnings as well as on total market income (defined as before tax income from all market sources including earnings, net selfemployment income, and asset income. $)^{6}$ All data are expressed in constant 1986 dollars using the CPI as the deflator. ${ }^{7}$ 
The first issue we explore with these data concerns the bias associated with annual income measures as opposed to a measure of permanent income. Solon (1992) suggests that multi-year averages of the father's income will reduce the importance of the transitory component of income, and increase the signal to noise ratio. The maximum number of periods over which we average is five (1978 through 1982).

Table 1 offers the descriptive statistics associated with each of the two measures for the subset of our data in which the average income of the father is greater than or equal to $\$ 1$ over the five available years. In the case of earnings, described in panel A, there are 339,951 father-son pairs with the father's average earnings ranging from $\$ 1$ to over $\$ 1.829$ million. The average earnings is $\$ 31,388$. There are 389,348 father-son pairs with information on total market income, with the average income of fathers being slightly higher at $\$ 35,586$.

The estimating equation incorporates the ages of both fathers and sons in order to correct for the fact that they are not being observed at the same point in their life cycle. Thus the model we use is:

$$
\begin{aligned}
& Y_{i}(t)=\beta_{0}+\beta_{1} \bar{Y}_{i}(t-1)+\beta_{2} \text { AgeSon }+\beta_{3} \text { AgeSon }^{2}+ \\
& \beta_{4} \text { AgeFather }+\beta_{5} \text { AgeFather }{ }^{2}+\varepsilon_{I}
\end{aligned}
$$

Where $\bar{Y}_{i}$ represents the natural logarithm of income possibly averaged over several consecutive years, and age is measured in years. ${ }^{8}$ Table 2 presents the estimates of $\beta_{1}$ from Least Squares regressions for both earnings and total market income. Each panel of the table offers the regression results using each of the various averages of father's income possible: the first column offering results from annual data, the second from successive two year averages, and so on to the single estimate using the five year average. Sample sizes vary for each estimation and are indicated, along with the standard errors, below the coefficient estimate. The downward bias of the single year estimates is evident: the estimates increase in magnitude with each year over which the average is taken. With respect to earnings in Panel A the estimates gradually converge to 0.131 using the full five years of data. The ratio of this coefficient to that of those based on annual data ranges from 1.15 to 1.3 , roughly about the lower bound of the range suggested by Solon when problems of an overly homogeneous sample are absent. The two estimates using four year averages are within two standard errors of this figure, as are the three estimated using three year averages. The general pattern is the same for total market income (see Panel B of Table 1). In this case the single-year estimates understate those based on the five-year average by about 30 to 60 percent. The elasticity between the market incomes of fathers and sons, at 0.194 in the case of the five year average, is higher than that between their earnings. In sum, these findings suggest that it is necessary to conduct the analysis using at least a three year average of the father's income, and that the five year horizon would appear to be long enough to reduce the bias due to transitory income fluctuations.

The robustness of these findings to the sample selection rules employed, the way in which adjustments for life cycle differences is made, and the choice of the father's income variable are assessed in Table 3. All of the results in this table are based upon five year averages of the father's income measure. The four rows labeled 1 in each of the panels of Table 3 repeat the results in the last column of Table 2. There are three major findings. First, the selection rules used to define the sample seem to have an important influence on the estimates of the elasticities. 
This influence seems to be restricted to whether individuals with zero (or negative) income are included in the sample before the average is calculated. If fathers must have at least $\$ 1$ of income in each of the five years over which the average is calculated (as opposed to the average being at least \$1) the earnings elasticity increases from 0.131 to 0.228 (see rows 1 and 2 in Panel A). The elasticity does not change much beyond this as the cut-off is raised further, reaching 0.242 at a cut-off of $\$ 3,000$. Further, the use of a $\$ 1$ dollar cut-off leads to similar estimates for the earnings-earnings and income-income elasticities, about 0.23 to 0.24 . Second, life-cycle differences between fathers and sons do not seem to make much of a difference. If no controls for age are included in the regression model the estimated elasticity is the same as those including a quadratic in father and son ages. This finding is robust to other specifications, to the inclusion of controls for the son's marital status, and to the use of all sons (not just the oldest). When the sample is restricted to just the 32 year olds the earnings elasticity is slightly higher (0.140), and when it is restricted to just the 29 year olds it is slightly lower (0.117). The market income elasticities seem to be almost completely unaffected by any of these considerations. Finally, the elasticity of the son's earnings with respect to the father's total market income is estimated to be 0.192 , essentially the same as the income-income elasticity. ${ }^{9}$

The sensitivity of the earnings results to sample selection rules is also highlighted in Panel D of the table, which contrasts the Least Squares estimates with quantile regressions about the median. The earnings results are not robust to the change in estimation strategy, but those for incomes are essentially the same. Least Squares and quantile regression yield results that are much closer when fathers are required to have at least $\$ 1$ of earnings in each of five years: 0.228 versus 0.206 .

Thus, taking into account some of the concerns raised in the literature-biases associated with measurement error, life-cycle adjustments, and the exclusion rules used in determining the analysis sample-our best estimate of the elasticity between father and sons earnings in the Canadian economy is probably around 0.2 , perhaps a little lower or a little higher depending upon the exclusion rules used to determine the sample.

\section{Representativeness and Accuracy of the Data}

This leaves aside the whole issue of the extent to which administrative data are comparable to survey data. There would seem to be two associated issues. The first concerns the representativeness of our sample. While we have a large data set, it may nonetheless be subject to a selection bias. For one thing in order to establish a father-son link we require that sons file an income tax return while still living in the family home at some point between 1982 and 1986. This implies that the son will have a SIN, and that it can be linked to the father's. Those sons who either do not have a father present, have left the household before filing an income tax return, or happen not to file an income tax return in 1995 will not be part of the analysis. As a result our data set likely under-represents the members of the cohort who had no attachment to the labour market during their teenage years, who left home before establishing an attachment, who lived in homes headed by lone mothers, or who possibly have little labour market attachment in their adult years. ${ }^{10}$ In all these cases it is conceivable that the data under-represent members of the cohort who are prone to low income as adults. Our selection rules will also exclude immigrants whose fathers entered the country after 1986.

The second issue involves the accuracy of reported earnings and income. In contrast to survey data there is, in the context of a progressive income tax system, a distinct incentive to under- 
report income to the tax authorities. However, what is particularly pertinent in the context of our objectives is whether these incentives are very strong, whether they vary across the income distribution, and if they have changed through time affecting fathers differently than sons. It is difficult to assess the degree to which income is not reported or under-reported, but it is conceivable that the incentive to do so may have been greater for the fathers in our sample than for the sons. During the late 1970s and early to midy 1980s there were as many as 10 income tax brackets, but in 1988 this was changed to just three. As a result there would have been a stronger incentive throughout the income distribution for fathers to slightly under-report their incomes than for sons, and would imply that intergenerational mobility will be overstated.

It should be noted, however, that problems of these sort are not unique to our data. For example, with respect to the sample selection problem Solon (1992, p.398) notes that the representativeness of the PSID for intergenerational analysis has likely been affected by sample attrition, low-income and high-income individuals being more likely to leave the survey. The analysis sample he uses represents not quite 60 percent of the original cohort of sons. Furthermore, income information from surveys are also subject to quality concerns. In fact, these concerns have led Statistics Canada to link survey respondents to their tax records and to use the tax data as the source of income information in the Survey of Labour and Income Dynamics, a longitudinal Canadian survey similar to the PSID. Michaud et al. (1995) compare the income information reported by a group of respondents to their income tax records and find that the survey responses tend to omit small amounts of income and to under-report income from certain sources, most notably self-employment income and interest and dividend income. The average amount of wage and salary income reported to the survey is essentially the same as that found in the tax files, and while there are about 2.4 percent of survey respondents who report some wage and salary income but have no corresponding information in the tax files, there are exactly the same fraction who have some earnings in the tax files but fail to report any to the survey (Michaud et al. 1995, tables 6 and 7).

In order to get a sense of some of these concerns we offer in Table 4 a comparison of our administrative data to a nationally representative survey, the Survey of Consumer Finances (SCF). This cross-sectional survey is conducted each May and asks respondents about the level and composition of their income during the previous year. We draw a sample of all those men 29 to 32 years of age for the 1995 survey year, calculate a measure of earnings and total market income that is as close as possible to the definitions used in our analysis, and compare the distribution to three samples from the administrative data: all those tax filers in 1995 who fall in the same age category, the subset of these we are able to link to a father, and finally the subset who are the oldest among multiple matches to the same father (and who form the basis for our analysis sample).

According to the SCF there were 1.015 million men aged 29 to 32 in 1995 . This contrasts with the 907,137 men in this age group who filed a 1995 income tax return, and the 497,242 we are able to link with a father. (This latter figure includes those who report zero or negative income, and those whose fathers report zero or negative income). In other words, the limitations of attempting to make a father-son link through the tax files in a way that allows us to obtain the father's income when the son is at a reasonably young age leads us to capture about 55 percent of all tax filers in our cohort, and about 49 percent of the entire cohort. ${ }^{11}$ There are thus two ways in which a sample selection bias could enter our analysis: not all individuals file an income tax return, not all filers are linked to their fathers. 
Our data tend to slightly overstate the median income of the population. The median earnings of this population is according to the SCF $\$ 18,700$, almost $\$ 800$ higher than the median earnings of tax filers, but about $\$ 2,750$ to $\$ 2,900$ lower than the filers with fathers and the oldest filers with fathers. A similar pattern holds in the case of market income. That being said, however, the most striking difference between the survey data and the administrative data concerns the extremes of the income distribution. The bottom percentile and even the bottom quintile tend to be higher in the SCF, while the top quintile and percentile are lower. The survey data clearly under-represent individuals in the very top of the income distribution: the maximum income, for example, is reported to be $\$ 157,000$ in the SCF but it is over $\$ 4$ million in the tax files. At the same time many more people with minimal earnings and incomes are captured in the tax files. The longer tails of the distribution, particularly at the upper end, contribute to greater cross-sectional inequality in the tax data as evidenced by the standard deviation of the log earnings and income. $^{12}$

It is difficult for us to assess the impact of excluding non-filers from the analysis, but we can assess the impact of being able to only link some of the filers to fathers. We divide the total number of tax filers who are 29 to 32 in 1995 into two groups, those linked to a father (and hence available for analysis), and those not linked (and hence excluded from analysis). To determine whether the potential selection bias makes a difference for the estimate of $\beta_{1}$ we estimate a regression model with sample selection using Heckman's two stage estimation method. The selection rule is modeled using a probit equation. Since this requires maximum likelihood estimation we choose a roughly 10 percent sample by using only those individuals whose SINs end with the digit 5 . The detailed results from the probit model are available upon request, but to summarize readability, the individuals in the analysis sample tend to be older; are much less likely to live in Toronto or Montreal, and to a slightly lesser extent British Columbia; and are more likely to be married than single, living in a common-law relationship, or divorced. The under-representation of our sample in the major metropolitan areas is due to the fact that most immigrants tend to settle in Toronto, Montreal, or Vancouver, and as mentioned are not captured in our analysis unless they arrived before 1986 and had fathers who were attached to the labour market. The other results accord with our prior that the sample under-represents those prone to lower incomes.

The results from the second stage of the estimation are presented in Table 5. Also presented for the sake of comparison are the results from a Least Squares regression using the same 10 percent sample. Fathers' earnings and incomes are measured using the five year average. The Least Squares results from this smaller sample do not yield statistically different results for the elasticity of son's earnings and income with respect to father's from those presented in Table 2. More importantly, the results from the sample selection regression are essentially the same as the Least Squares results. While the inverse Mill's ratio is negative and statistically significant, only the coefficient estimates for the son's age are different between the two sets of models. ${ }^{13}$

In this sense we conclude that our sample selection rules do not lend a major bias to the findings. This still does not address the consequences of the fact that non-filers are excluded from the analysis. Perhaps in this regard we should emphasize that Fortin and Lefebvre (1998) use a representative survey and a different methodology than we do, yet obtain essentially the same result. Their sample consists of 2,500 to 3,400 father-son pairs from the 1986 and 1994 General Social Survey. This survey does not offer parental income information, but it does capture their education and occupation. The authors use information on income by occupation from the 
Canadian census to predict parental employment incomes. Instrumental variables methods lead to an intergenerational elasticity between fathers and sons of 0.157 (with a standard error of 0.034) for a cohort born between 1955 and 1969 (Fortin and Lefebvre 1998, Table 4.4). They offer a host of results for other cohorts and different instruments but all of their findings are in the order of 0.2 . Thus, for a group of men roughly the same age as our cohort but with a nationally representative data set and with different econometric techniques (ones that are probably upwardly inconsistent), they obtain essentially the same result. This would seem to reinforce our conclusion that sample selection biases do not appear to have a major influence upon our findings.

\section{Non-Linearities}

The implication from these findings - that there is a good deal of intergenerational mobility in Canada and perhaps even more than in the U.S. - is reinforced when transition matrices of the sort presented earlier are examined. In deriving these we use the sample based upon a five year average of the father's earnings and a three year average of the son's earnings between 1993 and 1995, both corrected for life cycle effects. ${ }^{14}$ A transition matrix based upon quartiles is presented in the first panel of Table 6. Individuals born to fathers with incomes in the tails of the income distribution are certainly more likely to also have incomes in the tails. About 35 percent of sons born to fathers in the top quartile also had earnings in the top quartile, and about 33 percent of those born to fathers in the bottom quartile were also in the bottom as adults. The same figures at the bottom end of the income distribution are respectively 33 and 42 percent. In contrast, the middle part of the income distribution is characterized by close to perfect mobility.

A finer disaggregation indicates distinct asymmetries at the very extremes of the income distribution. This is illustrated by the decile transition matrix in Panel B of the table. Eighteen percent of those born to fathers with incomes in the top 10 percent of the income distribution also earned incomes that placed them in this decile, while almost 16 percent of those born in the bottom decile remain at the bottom. At the same time the chances of falling one decile for those born at the top are about the same as the chances of rising one decile for those born at the bottom.

The higher probabilities for the stayers at both the very top and very bottom of the fathers' income distribution has, in addition to representing non-linearity in the mobility process, something to do with the floors and ceilings in the design of transition matrices. If only a floorceiling effect were at work in say the quartile transition matrix - that is if the non-linear pattern were due only to the fact that those at the very top are restricted from further upward movement, and those at the very bottom from further downward mobility-we would expect only the top and bottom deciles to show significant spikes in the transition probabilities. In fact, the story is somewhat mixed. Substantially higher probabilities are evident for the top and bottom quartiles, and also for the top and bottom deciles. In other words, the finer disaggregation (that is the use of deciles) does indeed push the spike back. At the same time, however, the ninth and second deciles remain higher than neighbouring deciles. The same phenomenon occurs when percentiles are examined. A series of cross-sections of the earnings percentile transition matrix is presented in Figure 1. The very top and bottom percentiles show the sharpest spikes, revealing a floorceiling effect. However, those born to fathers at the 95 th percentile have a tendency to move up even further in the income distribution. This suggests the possibility of a non-linearity in the underlying process. This pattern may have a counterpart at the low end of the income 
distribution. For example, those born to fathers at the 5th percentile have a tendency, albeit a weaker one, to move even lower in the income distribution. The percentiles do in general reveal that the probability of upward mobility is lower for sons from low income backgrounds, while the probability of upward mobility is higher for sons from high income backgrounds. For example, the transition probabilities of moving within the lower quartile of the income distribution for those sons whose fathers were at the 5th and 10th percentiles are generally above the confidence interval two standard deviations on either side of 10 percent, but generally at or below it for movement into the top quartile. Conversely, those whose fathers were at the 95th percentile are more likely to be in the top quintile.

These findings underscore the need to reassess the regression results by taking non-linearities into account. We adopt non-parametric techniques as a way of both assessing the validity of the log-linear model, and as a way of exploring the nature of the possible non-linearities. Specifically, we employ nearest-neighbourhood estimators based upon locally weighted least squares regressions. ${ }^{15}$ This requires that the relationship between the independent and dependent variables (called the smooth) be continuous, but makes no explicit assumptions about the functional form linking them. In brief, the procedure involves defining a window of observations around a particular value of the independent variable, say $Y_{o}(t-1)$. In the case of nearestneighbourhood estimators this window is defined as a fraction of the total number of observations $(N)$, and termed the span $(\alpha)$. Each of the $\alpha N$ observations within this window are weighted using neighbourhood weights, $w\left(Y_{i}\right)$, such that the observations closest to $Y_{o}(t-1)$ receive the largest weight. A weighted least squares regression is then estimated using a polynomial of the regressor variable. The estimated coefficients from this regression are used to predict the value of the dependent variable at $Y_{o}(t-1)$. This represents one point on the smooth. A new value of $Y_{o}(t-1)$ and its neighbouring observations are then chosen and the process is repeated. ${ }^{16}$

There are three modeling choices that must be made: the weight function; the degree of the polynomial; and the span. Cleveland and Loader (1995) suggest that subject to certain broad characteristics the choice of the weight function is not crucial, and we follow them in using the tricubic function. ${ }^{17}$ Our primary concern is with the first derivative of the functional relationship linking father and son incomes. Since this is derived from the estimates of the degree of the polynomial we use a reasonably flexible functional form, the cubic. Higher order polynomials are likely to add little to the estimate of the first derivative at the cost of increasing the computational burden, but lower order polynomials may miss some of the curvature of the smooth at the cost of mis-specifying the first derivative.

The choice of $\alpha$ is the most crucial of the three to be made. This choice embodies the trade-off inherent in local regressions: that between bias and efficiency. A narrower span leads to lower bias, but higher standard errors. Since our concerns are to obtain a sense of the non-linearities in the smooth, and to assess the appropriateness of linear specification used in the existing literature we are more inclined to error on the side of a more efficient estimate at the risk of bias. We use a modified version of the Akaike Information Criterion (AIC) and graphical inspection to choose the most appropriate value of $\alpha .^{18}$

In order to ease the computational burden we employ a (roughly) $10 \%$ sample of our data using the same selection criterion discussed earlier. ${ }^{19}$ A scatter plot of the earnings and income data is presented in Figure 2. These are the raw data expressed as natural logarithms of income (adjusted 
for life cycle effects). There is clearly a positive correlation between father and son incomes. (The straight line is the least squares fit.) However, there seems also to be a concentration of data points with very low age adjusted log earnings levels (less than about -8 ) for the father, for the son, and for both. For some small segment of the population the age adjusted log earnings of the father is very low, and there is no apparent correlation with the son's income. Similarly a small number of sons earn minimal income in spite of their fathers' income. This pattern is also present, but to a lesser degree, in the case of total market income. These anomalous points are the reason that the results from the earnings-earnings regressions described in Table 2 are less robust than those from the income-income regressions. We believe these observations do not accurately approximate permanent earnings or income. ${ }^{20}$ In what follows we delete observations having a life-cycle adjusted log value of less than -6 .

A graph of the smooth relating father and son earnings and the associated first derivative are presented in the two panels of Figure 3. The optimal value of $\alpha$ (with respect to minimizing the AIC) is 0.84. This value is used to derive the smooth depicted in Panel A. (The straight line is the Least Squares fit.) The second Panel presents the corresponding elasticity. The predicted value from the log-linear regression model clearly lies outside of the 95 percent confidence interval of the nearest neighbourhood estimate (given by the broken lines), suggesting that it is a misspecification of the relationship between father and son earnings. The elasticity from the nonparametric model is clearly not constant. In this panel the vertical dotted lines represent the bottom and top percentile of the father's earnings distribution. At lower parts of the distribution the elasticity is zero or even negative and then rises reaching a value of almost 0.4 at the very top. Over the bulk of the distribution the elasticity displays an inverted V-shape, peaking at about 0.3 close to the median. ${ }^{21}$

Figure 4 brings together the elasticities from three alternative models. The results depicted in Panel B of Figure 3 are repeated as the line labeled EE, while the line labeled MM refers to the elasticity between the total market income of sons and fathers, and the line labeled EM refers to the elasticity between the sons' earnings and the fathers' total market income. In each case the span is chosen according to the AIC (for EM it is 0.84 and for MM it is 0.76). All of the elasticities display the inverted V pattern between the 1st and 99th percentiles, but the incomeincome elasticity is greater than the others throughout. It diverges sharply from them at or even below the top percentile and attains a value of almost 0.8 at the very top, more than double the earnings-earnings and earnings-income elasticities. A similar pattern is evident at the bottom of the income distribution, but not to the same extreme.

We are somewhat more confident of the results at the upper tail of the income distribution than at the bottom. As suggested earlier the selection rules used to construct our data lead to an underrepresentation of individuals who are likely to have low incomes. Although this selection bias does not influence the least squares results from the linear model, this may not be the case in the non-parametric model. We cannot therefore draw definitive conclusions about the nature of the intergenerational income elasticity below the first percentile, and in our view the nature of the process determining intergenerational income mobility at the very top and bottom of the income distribution requires in general more analysis because non-parametric estimators tend to be less reliable at the extremes of the distributions.

That being said the inverted $\mathrm{V}$ pattern seems to be a robust finding and has, along with the observed patterns at the upper tail, an interpretation in the context of the borrowing constraints 
model. As Becker and Tomes (1986) and Mulligan (1997) explain this model implies a nonlinear elasticity between parent and child earnings. Parents will invest in the human capital of children up to the point that the marginal returns between human capital investment and financial investment are the same, beyond that point further investments are made as financial transfers. Parents who are borrowing constrained may not be able to attain the optimal amount of human capital investment with the result that the correlation between parent and child earnings is stronger than it would otherwise be. However, the optimal amount of human capital investment also depends positively upon the child's ability. The parents who are most likely to be borrowing constrained are lower income parents of high ability children. If it is also the case that ability varies with the income of the parent-the higher the income of the parent, the higher (on average) the ability of the child-then the inverted $\mathrm{V}$ pattern that we uncover is not unreasonable. Over the lower half of the distribution the elasticity is rising because parental income is rather low but child ability is increasing so that the borrowing constraint becomes binding for a larger and larger fraction of the population. Over the upper half of the distribution the elasticity is falling because parental income gradually becomes high enough to finance postsecondary education, and the borrowing constraint is relaxed even though child ability continues to rise. As parental income increases further financial transfers made to children become increasingly more important. This is reflected in a much higher elasticity between the incomes of fathers and sons than between their earnings.

\section{Conclusion}

Our exploration of the degree of intergenerational income mobility among Canadian men leads to the conclusion that the intergenerational elasticity of father-son earnings and incomes is on average about 0.2 , an estimate that until recently was taken as the consensus value in the United States. This finding is robust to several measurement and methodological issues raised in the existing literature, including measurement error associated with transitory income shocks, and life cycle differences between fathers and sons. However, the earnings-earnings elasticities can be sensitive to the cut-off rules used to define the analysis sample. Since we use administrative data associated with the Canadian income tax system we also pay specific attention to the possibility that sample selection bias may influence our results. In fact, we find that our data tend to under-represent those on the margins of the labour market, but that this does not influence our estimate of the intergenerational elasticity of father and son incomes. At the same time, however, we also uncover significant non-linearities in the relationship between father and son incomes. The use of non-parametric methods leads to the suggestion that log-linear models imply a misspecification of the data generating process. Over the course of the lower half of the fathers' distribution the elasticity between father and son earnings rises from zero to about 0.3 , and then falls to 0.1 over the upper half. It rises again at the very top of the income distribution reaching a value of about 0.4 the top percentile. The elasticity between total market incomes is slightly higher and follows a similar pattern, but rises to almost 0.8 at the top end of the distribution. This pattern can be interpreted in the context of a borrowing constraints model of parental investment in the human capital of children if child ability is assumed to be positively correlated with parental income.

In addition, Mulligan (1997) points out that policy can influence the degree of intergenerational mobility: graduated estate taxes, progressive income taxes, and the subsidization of college and university education may all be expected to influence the human capital investments that parents make in their children. If the degree of intergenerational mobility is the same across countries 
then it may be that differences in these policies have little impact. However, this may not be the case if broader societal factors associated with familial values and social structures also play a role. Canada may be a particularly relevant country to study and juxtapose against the many studies of the United States since, as Card and Freeman (1993) point out, the two countries have very similar labour markets, cultural traditions, and living standards. These similarities raise the possibility of more clearly distinguishing the impact of institutional/policy differences on labour market outcomes. In particular, there is no estate tax in Canada, income tax rates are in general higher and more progressive than in the United States, and there has historically been greater access to high quality post-secondary education.

The results from our log-linear specification offer no evidence that the intergenerational elasticity of earnings or income is higher than 0.25 , substantially below the 0.4 to 0.5 estimates found by many researchers using U.S. data. These results may, when coupled with more institutional information, contribute to an understanding of the impact these policies may have on intergenerational mobility. Our analysis highlights the value of administrative data to this exercise, emphasizes the possibility that the log-linear model is a mis-specification of the relationship between father and son earnings, and consequently underscores the need to adopt flexible econometric techniques to explore potential non-linearities in this relationship. 
Table 1

DESCRIPTIVE STATISTICS: EARNINGS AND TOTAL MARKET INCOME

\begin{tabular}{|c|c|c|c|c|c|c|c|c|c|}
\hline & Average & $\begin{array}{l}\text { Standard } \\
\text { Deviation }\end{array}$ & Minimum & $\begin{array}{l}1^{\text {st }} \\
\text { Percentile }\end{array}$ & $\begin{array}{l}25^{\text {th }} \\
\text { Percentile }\end{array}$ & Median & $\begin{array}{l}75^{\text {th }} \\
\text { Percentile }\end{array}$ & $\begin{array}{l}99^{\text {th }} \\
\text { Percentile }\end{array}$ & Maximum \\
\hline A. Total Earnings & \multicolumn{9}{|c|}{ Number of Observations $=339,951$} \\
\hline Son's Earnings in 1995 & 25,219 & 20,960 & 1 & 128 & 14,504 & 24,345 & 33,512 & 68,667 & $3,692,884$ \\
\hline Father's Earnings 1978-82 & 31,388 & 22,246 & 1 & 1.2 & 20,470 & 29,750 & 39,597 & 93,518 & $1,829,229$ \\
\hline Log Son's Earnings in 1995 & 9.796 & 1.239 & 0 & 4.852 & 9.582 & 10.100 & 10.420 & 11.137 & 15.122 \\
\hline Log Father's Earnings 1978-82 & 9.981 & 1.459 & 0 & 0.182 & 9.927 & 10.301 & 10.587 & 11.446 & 14.419 \\
\hline B. Total Market Income & \multicolumn{9}{|c|}{ Number of Observations $=389,348$} \\
\hline Son's Market Income in 1995 & 25,386 & 24,158 & 1 & 314 & 13,842 & 23,822 & 33,345 & 77,324 & $4,161,596$ \\
\hline Father's Market Income 1978-82 & 35,586 & 35,275 & 1 & 2,627 & 22,148 & 31,372 & 42,327 & 130,539 & $8,105,156$ \\
\hline Log Son's Market Income in 1995 & 9.820 & 1.085 & 0 & 5.749 & 9.535 & 10.078 & 10.415 & 11.256 & 15.241 \\
\hline Log Father's Market Income 1978-82 & 10.268 & 0.738 & 0 & 7.874 & 10.005 & 10.354 & 10.653 & 11.779 & 15.908 \\
\hline
\end{tabular}


Table 2

\section{THE EFFECT OF TRANSITORY FLUCTUATIONS ON THE LEAST SQUARES ESTIMATES} OF THE INTEREGENERATIONAL EARNINGS AND INCOME ELASTICITIES

\begin{tabular}{ccccc}
\hline Single Year & $\begin{array}{c}\text { Two Year } \\
\text { Average }\end{array}$ & $\begin{array}{c}\text { Three Year } \\
\text { average }\end{array}$ & $\begin{array}{c}\text { Four Year } \\
\text { Average }\end{array}$ & $\begin{array}{c}\text { Five Year } \\
\text { Average }\end{array}$ \\
\hline
\end{tabular}

\section{A. Father's Log Earnings}

\begin{tabular}{|c|c|c|c|c|c|}
\hline 1978 & $\begin{array}{l}0.114 \\
(0.003) \\
{[339,558]}\end{array}$ & $\begin{array}{l}0.106 \\
(0.003)\end{array}$ & & & \\
\hline \multirow[t]{2}{*}{1979} & $\begin{array}{l}0.110 \\
(0.003)\end{array}$ & {$[343,551]$} & $\begin{array}{l}0.123 \\
(0.003)\end{array}$ & & \\
\hline & {$[340,824]$} & $\begin{array}{l}0.113 \\
(0.003)\end{array}$ & {$[341,527]$} & $\begin{array}{l}0.126 \\
(0.003)\end{array}$ & \\
\hline \multirow[t]{2}{*}{1980} & $\begin{array}{l}0.101 \\
(0.002)\end{array}$ & {$[342,433]$} & $\begin{array}{l}0.123 \\
(0.003)\end{array}$ & {$[341,181]$} & $\begin{array}{l}0.131 \\
(0.003)\end{array}$ \\
\hline & {$[341,283]$} & $\begin{array}{l}0.120 \\
(0.003)\end{array}$ & {$[342,038]$} & $\begin{array}{l}0.129 \\
(0.003)\end{array}$ & {$[339,951]$} \\
\hline \multirow[t]{2}{*}{1981} & $\begin{array}{l}0.100 \\
(0.002)\end{array}$ & {$[341,843]$} & $\begin{array}{l}0.135 \\
(0.003)\end{array}$ & {$[341,044]$} & \\
\hline & {$[342,901]$} & $\begin{array}{l}0.127 \\
(0.003)\end{array}$ & {$[337,748]$} & & \\
\hline 1982 & $\begin{array}{l}0.104 \\
(0.003) \\
{[333,498]}\end{array}$ & {$[337,793]$} & & & \\
\hline
\end{tabular}

\section{B. Father's Log Total Market Income}

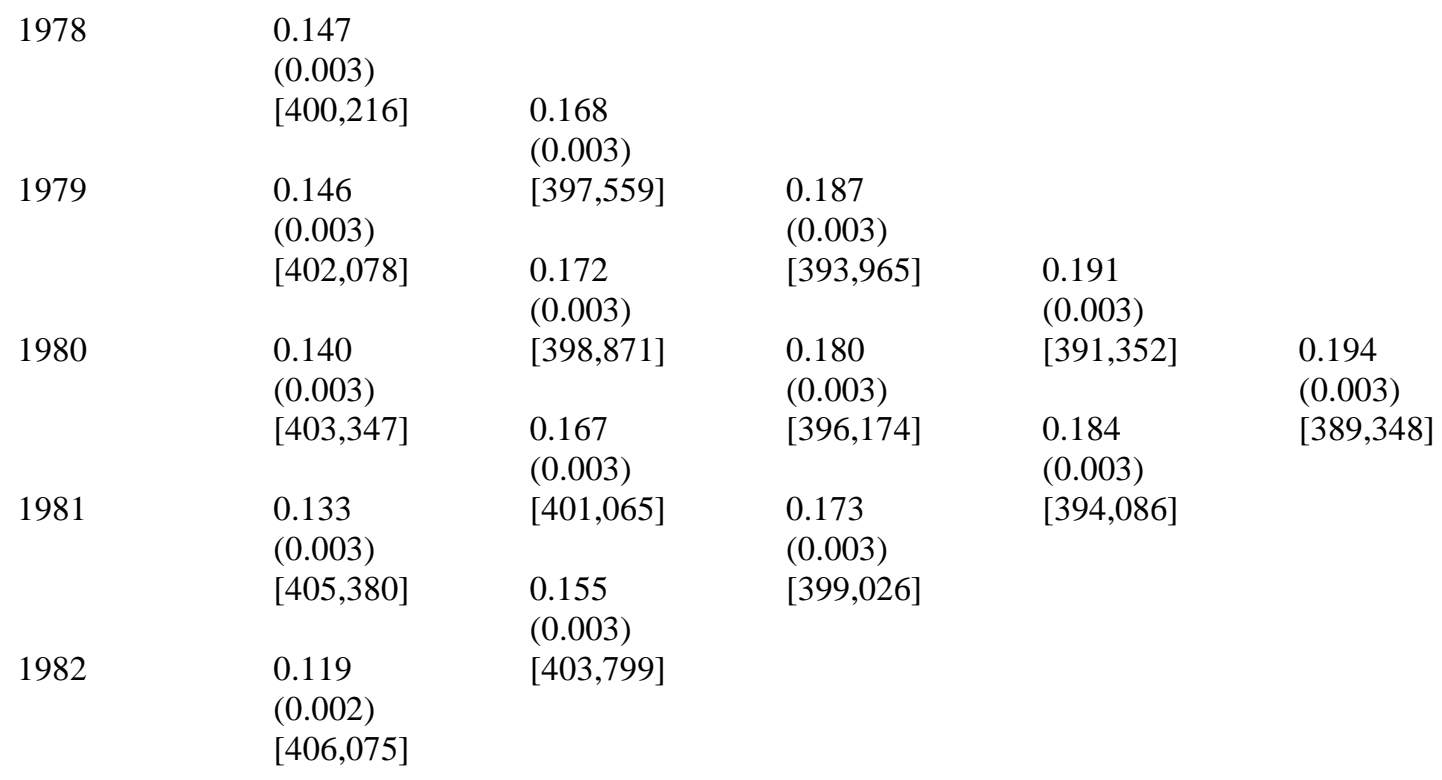

( ) indicates standard errors based upon White's heteroscedastic robust estimator, [ ] indicates sample size 


\section{Table 3}

INTERGENERATIONAL ELASTICITIES FOR VARIOUS SAMPLES AND SPECIFICATIONS: FATHER AND SON EARNINGS AND MARKET INCOME

\begin{tabular}{|c|c|c|c|c|}
\hline & \multicolumn{2}{|c|}{ Earnings } & \multicolumn{2}{|c|}{ Total Market Income } \\
\hline & Elasticity & $\begin{array}{l}\text { Standard } \\
\text { Error }\end{array}$ & Elasticity & $\begin{array}{l}\text { Standard } \\
\text { Error }\end{array}$ \\
\hline \multicolumn{5}{|l|}{ A. Sample Selection Rules } \\
\hline 1. Average Income Over Five Years $\geq \$ 1$ & 0.131 & $(0.003)$ & 0.194 & $(0.003)$ \\
\hline 2. Income in Each of Five Years $\geq \$ 1$ & 0.228 & $(0.006)$ & 0.236 & $(0.004)$ \\
\hline 3. Income in Each of Five Years $\geq \$ 100$ & 0.227 & $(0.003)$ & 0.231 & $(0.003)$ \\
\hline 4. Income in Each of Five Years $\geq \$ 1,000$ & 0.237 & $(0.003)$ & 0.239 & $(0.002)$ \\
\hline 5. Income in Each of Five Years $\geq \$ 3,000$ & 0.242 & $(0.003)$ & 0.236 & $(0.002)$ \\
\hline \multicolumn{5}{|l|}{ B. Life Cycle Adjustments } \\
\hline 1. Quadratic in Age of Fathers and Sons & 0.131 & $(0.003)$ & 0.194 & $(0.003)$ \\
\hline 2. No Controls for Age & 0.131 & $(0.003)$ & 0.193 & $(0.003)$ \\
\hline 3. Dummy variables for Age of Sons & 0.131 & $(0.003)$ & 0.194 & $(0.003)$ \\
\hline 4. Quartic in Age of Fathers and Sons & 0.132 & $(0.003)$ & 0.196 & $(0.003)$ \\
\hline 5. Oldest Sons born in 1963 & 0.140 & $(0.006)$ & 0.197 & $(0.006)$ \\
\hline 6. Oldest Sons born in 1966 & 0.117 & $(0.007)$ & 0.197 & $(0.008)$ \\
\hline 7. All Siblings & 0.129 & $(0.003)$ & 0.196 & $(0.003)$ \\
\hline 8. Controls for Marital Status & 0.134 & $(0.003)$ & 0.193 & $(0.003)$ \\
\hline \multicolumn{5}{|l|}{ C. Choice of Regressor } \\
\hline 1. Earnings & 0.131 & $(0.003)$ & & \\
\hline 2. Total Market Income & 0.192 & $(0.004)$ & & \\
\hline \multicolumn{5}{|l|}{ D. Estimation Method } \\
\hline \multicolumn{5}{|l|}{ Average Income Over Five Years $\geq \$ 1$} \\
\hline 1. Least Squares & 0.131 & $(0.003)$ & 0.194 & $(0.003)$ \\
\hline 2. Median Regression & 0.068 & $(0.001)$ & 0.192 & $(0.002)$ \\
\hline \multicolumn{5}{|l|}{ Income in Each of Five Years $\geq \$ 1$} \\
\hline 3. Least Squares & 0.228 & $(0.006)$ & 0.236 & $(0.004)$ \\
\hline 4. Median Regression & 0.206 & $(0.002)$ & 0.225 & $(0.002)$ \\
\hline
\end{tabular}


Table 4

A COMPARISON OF INCOME STATISTICS FROM THE SURVEY OF CONSUMER FINANCES AND ADMINISTRATIVE INCOME TAX FILES MEN AGED 29 TO 32 (1995 EARNINGS AND TOTAL MARKET INCOME MEASURED IN 1986 DOLLARS)

\begin{tabular}{|c|c|c|c|c|c|c|c|c|c|c|c|c|c|c|}
\hline & Number & Average & $\begin{array}{l}\text { Standard } \\
\text { Deviation }\end{array}$ & Skewness & Kurtosis & Minimum & $\begin{array}{l}\text { Bottom } \\
\text { Percentile }\end{array}$ & $\begin{array}{l}\text { Bottom } \\
\text { Quintile }\end{array}$ & $\begin{array}{l}\text { Bottom } \\
\text { Quartile }\end{array}$ & Median & $\begin{array}{l}\text { Top } \\
\text { Quartile }\end{array}$ & $\begin{array}{l}\text { Top } \\
\text { Quintile }\end{array}$ & $\begin{array}{l}\text { Top } \\
\text { Percentile }\end{array}$ & Maximum \\
\hline \multicolumn{15}{|l|}{ A. EARNINGS } \\
\hline \multicolumn{15}{|l|}{ 1. All Earners } \\
\hline SCF & $1,015,000$ & 19,619 & 15,142 & 0.7 & 0.7 & 0 & 0 & 0 & 6,861 & 18,727 & 29,963 & 44,944 & 59,925 & 137,828 \\
\hline All Tax Filers & 907,137 & 19,107 & 20,142 & 28.8 & $3,109.6$ & 0 & 0 & 0 & 4,818 & 17,948 & 29,007 & 45,130 & 62,665 & $3,692,884$ \\
\hline Filers with Father & 497,242 & 21,853 & 20,594 & 28.9 & $3,273.5$ & 0 & 0 & 0 & 8,738 & 21,479 & 31,572 & 47,345 & 65,956 & $3,692,884$ \\
\hline Oldest Filers & 448,196 & 21,987 & 21,027 & 30.0 & $3,339.9$ & 0 & 0 & 0 & 8,805 & 21,622 & 31,738 & 47,545 & 66,431 & $3,692,884$ \\
\hline \multicolumn{15}{|l|}{ 2. Earnings >0 } \\
\hline SCF & 860,000 & 23,141 & 13,746 & 0.8 & 1.4 & 0.75 & 698 & 2,996 & 12,734 & 22,472 & 31,461 & 46,442 & 62,468 & 137,828 \\
\hline All Tax Filers & 769,089 & 22,537 & 20,031 & 34.2 & $3,726.9$ & 1 & 1 & 1,588 & 11,161 & 21,336 & 30,954 & 46,650 & 65,135 & $3,692,884$ \\
\hline Filers with Father & 439,453 & 24,728 & 20,219 & 34.3 & $3,967.0$ & 1 & 85 & 2,572 & 13,939 & 23,801 & 33,025 & 48,515 & 68,040 & $3,692,884$ \\
\hline Oldest Filers & 396,053 & 24,881 & 20,695 & 35.4 & $4,007.9$ & 1 & 86 & 2,572 & 14,059 & 23,963 & 33,196 & 48,747 & 68,453 & $3,692,884$ \\
\hline \multicolumn{15}{|l|}{ 3. log Earnings } \\
\hline SCF & 860,000 & 9.79 & 0.89 & -2.1 & 8.7 & -0.29 & 6.55 & 8.01 & 9.45 & 10.02 & 10.36 & 10.75 & 11.04 & 11.83 \\
\hline All Tax Filers & 769,089 & 9.58 & 1.49 & -3.9 & 20.6 & 0 & 0 & 7.37 & 9.32 & 9.97 & 10.34 & 10.75 & 11.08 & 15.12 \\
\hline Filers with Father & 439,453 & 9.76 & 1.28 & -4.3 & 26.3 & 0 & 4.44 & 7.85 & 9.54 & 10.08 & 10.41 & 10.79 & 11.13 & 15.12 \\
\hline Oldest Filers & 396,053 & 9.77 & 1.28 & -4.3 & 26.3 & 0 & 4.45 & 7.85 & 9.55 & 10.08 & 10.41 & 10.79 & 11.13 & 15.12 \\
\hline \multicolumn{15}{|c|}{ B. MARKET INCOME } \\
\hline \multicolumn{15}{|l|}{ 1. All Income } \\
\hline SCF & $1,015,000$ & 22,131 & 15,908 & 1.5 & 6.5 & $-22,548$ & 0 & 0 & 11,158 & 21,034 & 30,592 & 47,926 & 72,420 & 157,303 \\
\hline All Tax Filers & 907,137 & 20,593 & 22,835 & 35.0 & $3,700.5$ & $-328,069$ & 0 & 0 & 7,528 & 18,985 & 29,607 & 46,572 & 69,584 & $4,161,596$ \\
\hline Filers with Father & 497,242 & 23,637 & 23,893 & 36.3 & $3,850.9$ & $-149,981$ & 0 & 0 & 11,441 & 22,419 & 32,279 & 49,105 & 74,834 & $4,161,596$ \\
\hline \multirow{2}{*}{\multicolumn{15}{|c|}{ 2. Income $>0$}} \\
\hline & & & & & & & & & & & & & & \\
\hline SCF & 954,000 & 23,552 & 15,329 & 1.7 & 7.7 & 0.75 & 749 & 3,314 & 12,446 & 22,362 & 31,461 & 48,554 & 72,584 & 157,303 \\
\hline All Tax Filers & 826,944 & 22,632 & 22,891 & 37.9 & $4,006.8$ & 1 & 40 & 1,818 & 10,699 & 20,834 & 30,727 & 47,512 & 71,790 & $4,161,596$ \\
\hline Filers with Father & 471,280 & 24,979 & 23,810 & 38.5 & $4,110.8$ & 1 & 288 & 3,038 & 13,443 & 23,391 & 32,921 & 49,707 & 76,090 & $4,161,596$ \\
\hline Oldest Filers & 424,884 & 25,140 & 24,421 & 39.4 & $4,116.9$ & 1 & 288 & 3,046 & 13,533 & 23,536 & 33,095 & 49,996 & 76,869 & $4,161,596$ \\
\hline \multicolumn{15}{|l|}{ 3. log Income } \\
\hline SCF & 954,000 & 9.79 & 0.91 & -2.10 & 9.40 & -0.29 & 6.62 & 8.11 & 9.43 & 10.02 & 10.36 & 10.79 & 11.19 & 11.97 \\
\hline All Tax Filers & 826,944 & 9.60 & 1.37 & -3.67 & 20.28 & 0 & 3.69 & 7.51 & 9.28 & 9.94 & 10.33 & 10.77 & 11.18 & 15.24 \\
\hline Filers with Father & 471,280 & 9.80 & 1.10 & -3.56 & 22.84 & 0 & 5.66 & 8.02 & 9.51 & 10.06 & 10.40 & 10.81 & 11.24 & 15.24 \\
\hline Oldest Filers & 424,884 & 9.80 & 1.10 & -3.55 & 22.68 & 0 & 5.66 & 8.02 & 9.51 & 10.07 & 10.41 & 10.82 & 11.25 & 15.24 \\
\hline
\end{tabular}

SCF refers to the Survey of Consumer Finances 1995. All statistics from this survey are based upon weighted data from a sample of 2,587 men 29 to 32 years of age.

All Tax Filers refers to income tax information on all 29 to 32 year old men who filed an income tax return (a T1 form) for the tax year 1995.

Filers with Father refers to income tax information on 29 to 32 year old men who were matched to a father in 1982.

Oldest Filers refers to a subsample of Filers with Father consisting of the oldest of all individuals having the same father. 
Table 5

LEAST SQUARES AND SAMPLE SELECTION REGRESSIONS OF THE ELASTICITY OF SON'S EARNINGS AND INCOME WITH RESPECT TO FATHER'S EARNINGS AND INCOME

\begin{tabular}{|c|c|c|c|c|}
\hline & \multicolumn{2}{|c|}{ Earnings } & \multicolumn{2}{|c|}{ Total Market Income } \\
\hline & $\begin{array}{c}\text { Not } \\
\text { Corrected for } \\
\text { Sample } \\
\text { Selection Bias }\end{array}$ & $\begin{array}{l}\text { Corrected for } \\
\text { Sample } \\
\text { Selection Bias }\end{array}$ & $\begin{array}{c}\text { Not } \\
\text { Corrected for } \\
\text { Sample } \\
\text { Selection Bias }\end{array}$ & $\begin{array}{l}\text { Corrected for } \\
\text { Sample } \\
\text { Selection Bias }\end{array}$ \\
\hline Constant & $\begin{array}{l}0.848 \\
(6.45)\end{array}$ & $\begin{array}{c}14.8 \\
(6.99)\end{array}$ & $\begin{array}{l}-0.479 \\
(5.19)\end{array}$ & $\begin{array}{c}14.7 \\
(5.86)\end{array}$ \\
\hline Log Father's Earnings/Income & $\begin{array}{c}0.145 \\
(0.005)\end{array}$ & $\begin{array}{c}0.145 \\
(0.005)\end{array}$ & $\begin{array}{c}0.194 \\
(0.008)\end{array}$ & $\begin{array}{c}0.199 \\
(0.008)\end{array}$ \\
\hline Son's Age & $\begin{array}{c}0.416 \\
(0.422)\end{array}$ & $\begin{array}{l}-0.391 \\
(0.457)\end{array}$ & $\begin{array}{c}0.468 \\
(0.340)\end{array}$ & $\begin{array}{l}-0.415 \\
(0.383)\end{array}$ \\
\hline Son's Age Squared & $\begin{array}{c}-0.00612 \\
(0.007)\end{array}$ & $\begin{array}{c}0.00625 \\
(0.007)\end{array}$ & $\begin{array}{c}-0.00685 \\
(0.006)\end{array}$ & $\begin{array}{c}0.00657 \\
(0.006)\end{array}$ \\
\hline Father's Age & $\begin{array}{l}0.0225 \\
(0.012)\end{array}$ & $\begin{array}{l}0.0259 \\
(0.012)\end{array}$ & $\begin{array}{c}0.0170 \\
(0.0094)\end{array}$ & $\begin{array}{c}0.0214 \\
(0.0094)\end{array}$ \\
\hline Father's Age Squared & $\begin{array}{l}-0.00025 \\
(0.0001)\end{array}$ & $\begin{array}{l}-0.00027 \\
(0.0001)\end{array}$ & $\begin{array}{c}-0.00018 \\
(0.0001)\end{array}$ & $\begin{array}{l}-0.00021 \\
(0.0001)\end{array}$ \\
\hline$\lambda$ & & $\begin{array}{l}-0.925 \\
(0.067)\end{array}$ & & $\begin{array}{l}-1.01 \\
(0.055)\end{array}$ \\
\hline Adjusted $\mathrm{R}^{2}$ & 0.0303 & 0.0365 & 0.0205 & 0.0309 \\
\hline Number of Observations & \multicolumn{2}{|c|}{33,660} & \multicolumn{2}{|c|}{38,637} \\
\hline
\end{tabular}

Note: The samples used consist of all those father-son pairs in which the (eldest) son's SIN ends with 5, and had no missing values for the variables used in the probit selection equation. The probit results are given in the appendix. $\lambda$ is the inverse Mill's ratio derived from these results. Father's earnings and income are defined as the logarithm of the annual average between 1978 and 1982. This average had to be equal to or greater than one to be included in the sample.

( ) indicates the standard error of the estimate. 
Table 6

\section{FATHER-SON EARNINGS TRANSITION MATRICES}

A. Quartile Transition Matrix

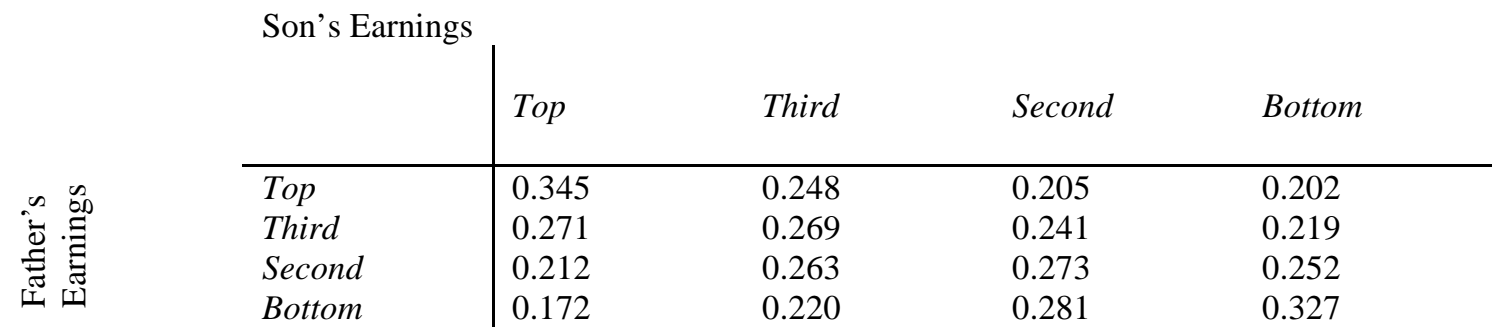

B. Decile Transition Matrix

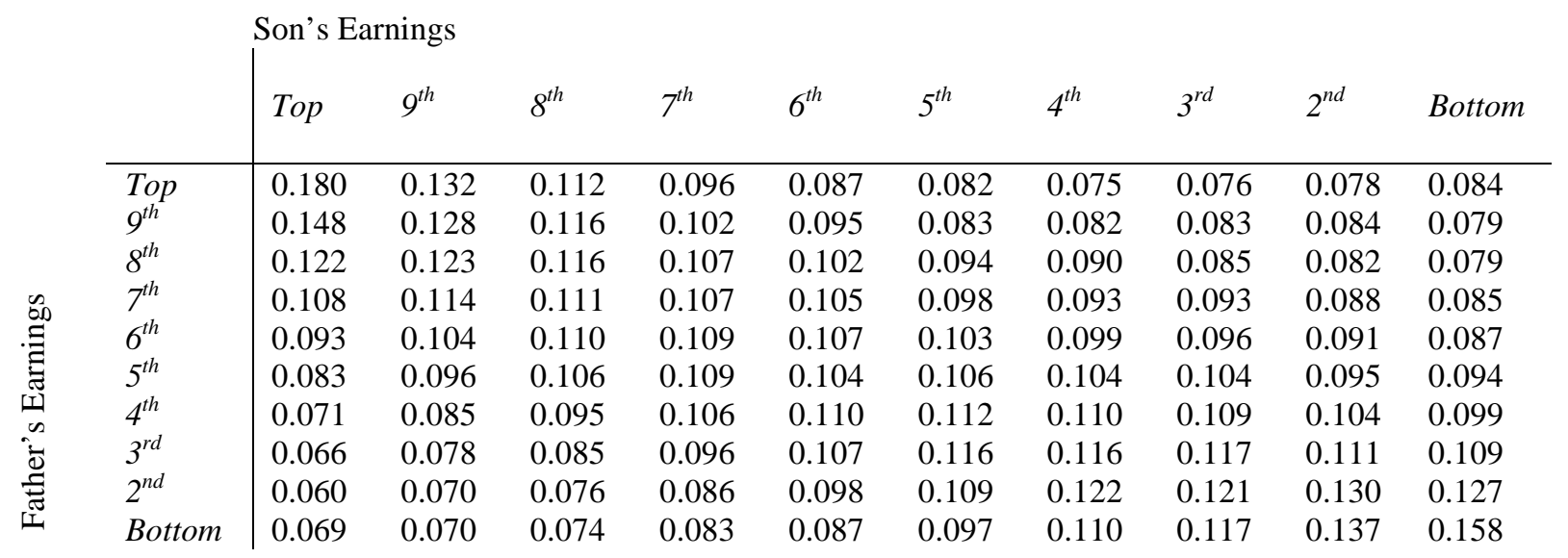

Note: Life cycle adjusted data from a sample of 334,018 father-son observations. The son's earnings are averaged over 1993 to 1995 and age adjusted as described in the text, and the father's earnings are averaged over 1978 and 1982 and age adjusted. The Immobility Index for the quartile transition matrix is 0.304. For the decile transition matrix it is 0.126 .

Source: Calculations by Authors from Administrative Income tax data, Statistics Canada 


\section{Figure 1}

\section{PROBABILITY OF SON'S EARNINGS PERCENTILE GIVEN FATHER'S EARNINGS PERCENTILE}
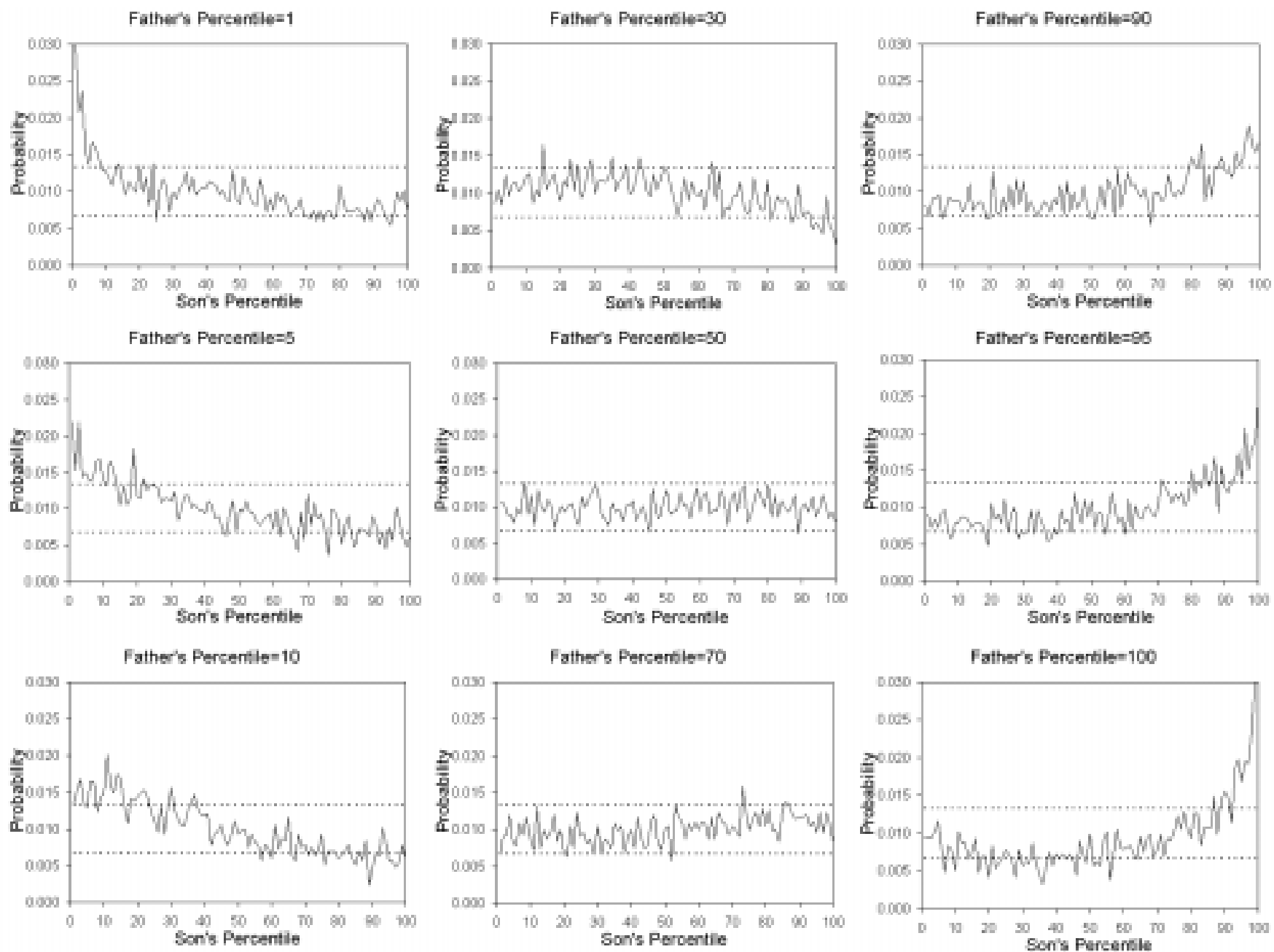

Note: Father and son incomes are age adjusted as described in the text. The sample size is 334,018 . The 1 st percentile for the top left hand graph (Father's Percentile $=1$ ) is out of range at 0.0329 . The 99th and 100th percentiles for the bottom right hand graph (Father's Percentile $=100$ ) are also out of range at 0.0371 and 0.0895 . 
Figure 2

\section{SCATTER PLOT OF SON'S LOG EARNINGS AGAINST \\ FATHER'S LOG EARNINGS AND LOG MARKET INCOME}

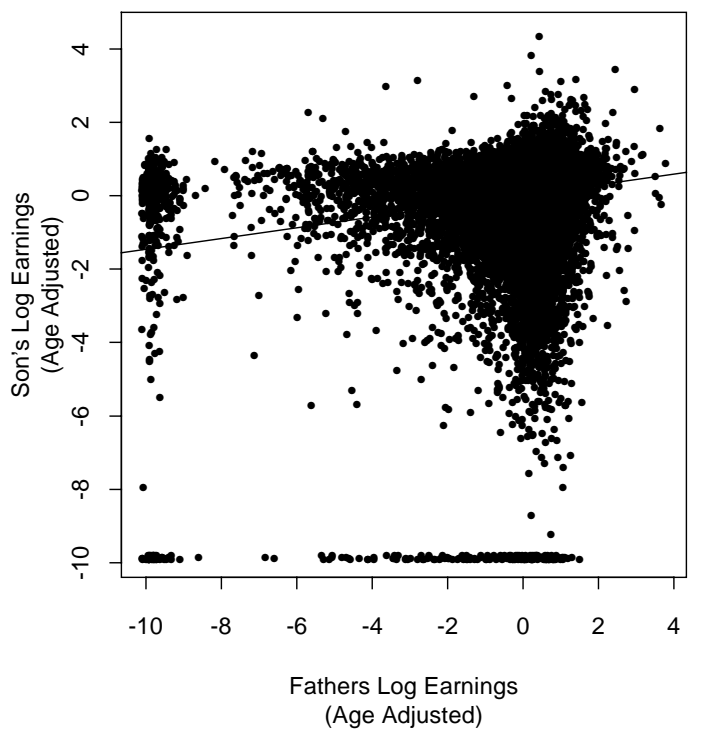

A. Son's Earnings - Father's Earnings

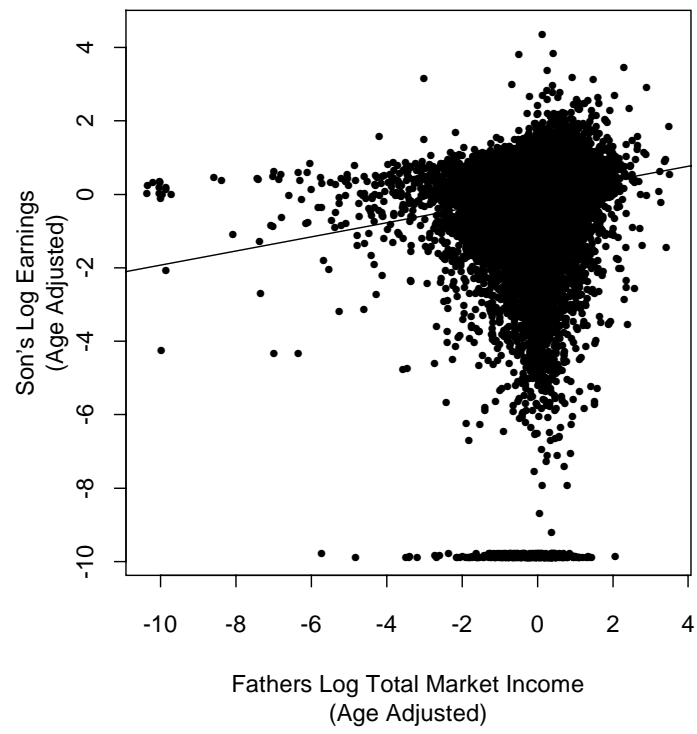

B. Son's Earnings - Father's Market Income

Note: The data are age adjusted, and expressed as logarithms with the straight lines being the least squares estimates. In Panel A there are 33,660 observations, and the slope (standard error) of the least squares line is 0.146 (0.0047). In Panel B the number of observations is 36,039 , and the slope (standard error) of the least squares line is 0.193 (0.0094). 
Figure 3

\section{NEAREST NEIGHBOURHOOD ESTIMATES OF THE RELATIONSHIP BETWEEN FATHER AND SON EARNINGS}

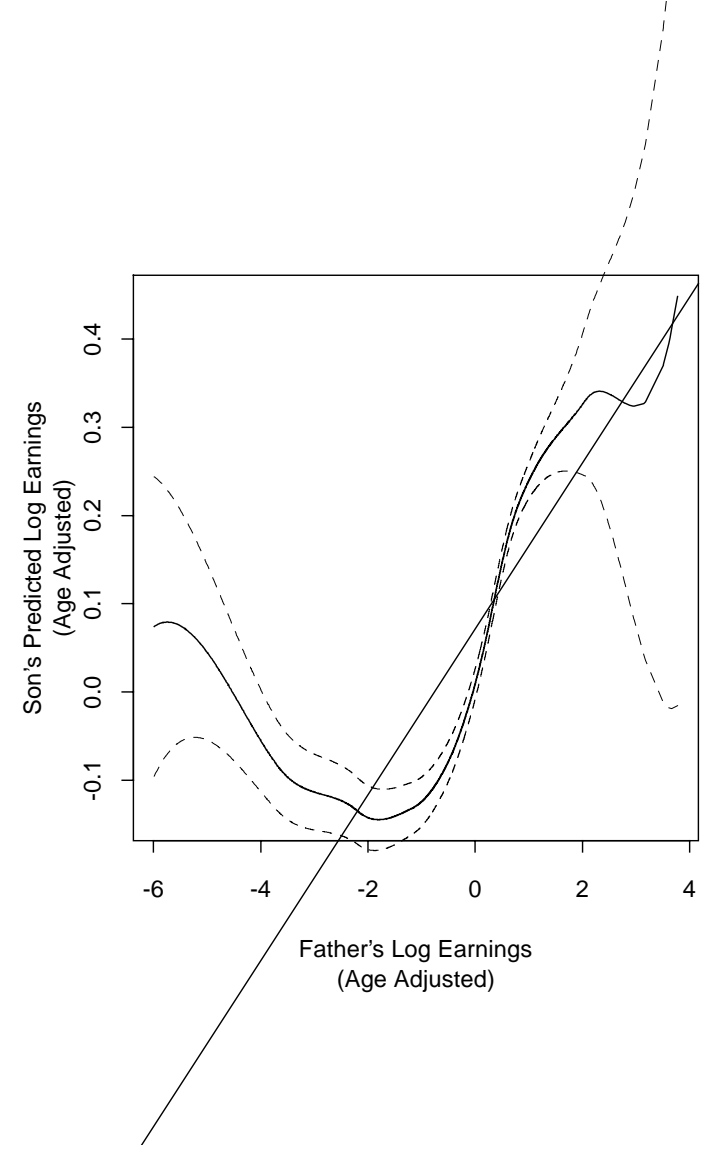

A. Predicted Values

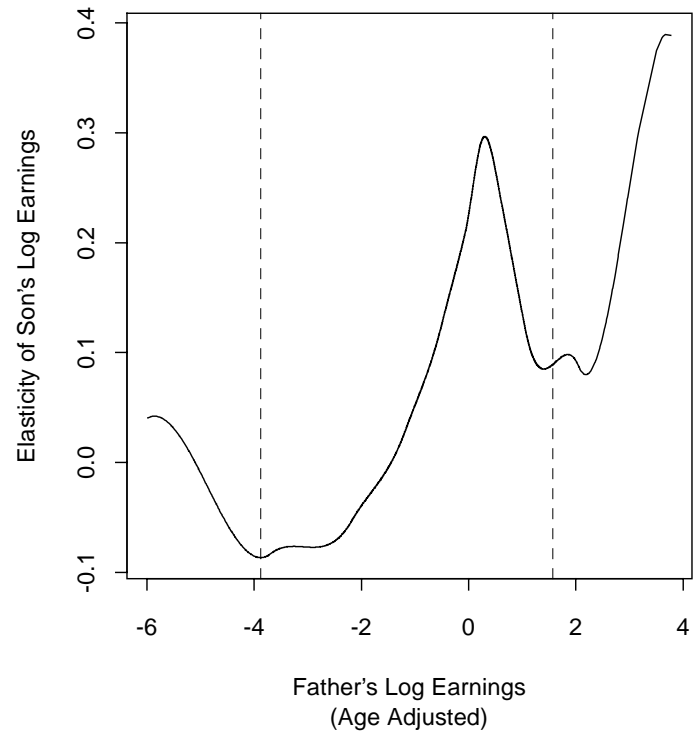

B. Elasticity

Note: Panel A presents the predicted relationship between Father and Son life cycle adjusted log Earnings using the estimation procedure described in the text with a span of 0.84. The dashed lines are two standard errors from the estimated relationship, and the straight line is the least squares estimate. Panel B is the estimated elasticity, with the vertical dashed lines representing the $1^{\text {st }}$ and $99^{\text {th }}$ percentiles of the father's age adjusted log earnings. 
Figure 4

THE ELASTICITY OF SON'S EARNINGS AND TOTAL MARKET INCOME

WITH RESPECT TO FATHER'S EARNINGS AND TOTAL MARKET INCOME

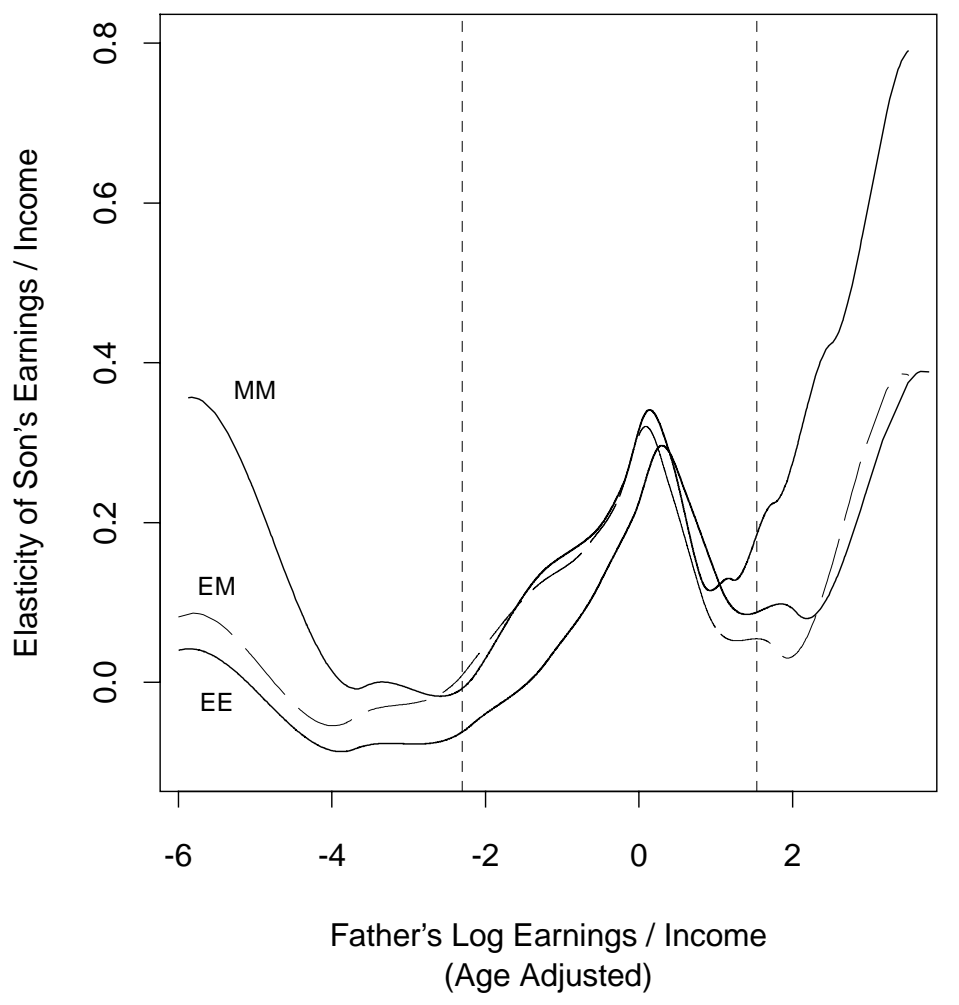

Note: The line labeled MM refers to the elasticity between the total market incomes of sons and fathers, the line labeled EM refers to the elasticity between the earnings of sons and the total market income of fathers, and the line EE refers to the elasticity between father and son earnings. All of the results are based upon Nearest Neighbourhood estimation described in the text. For $\mathrm{MM}$ the span is 0.76 , for EM and EE it is 0.84 . The vertical broken lines represent the $1^{\text {st }}$ and $99^{\text {th }}$ percentiles of the father's age-adjusted log total market income. 


\section{Appendix}

\section{Data Development and Definitions}

We link the Social Insurance Numbers (SINs) of fathers and sons by using the T1 Family File (T1FF). The SIN is a unique individual identifier, and the T1FF is a dataset of T1 records that has been processed in order to match members of each tax filer's family. (T1 forms are the main annual tax returns filed by individuals in Canada, and the T1FF incorporates the universe of tax filers.) A variety of matching strategies are employed to identify family members, and imputation processes are used to add non-tax filing members of the family and to complete missing information. Couples (including spouses and common law couples) are linked using SIN codes and spousal SIN codes when indicated on the T1, as well as name and address information. Children are matched to their parents using name and address fields. More detail on the construction of the T1FF is given by Harris and Lucaciu (1994).

Father-son pairs are drawn from the T1FF for several years (1982 to 1986) in order to improve the coverage of our sample and reduce the scope of a sample selection bias. The algorithm is presented in Figure A-1. We retain the earliest father-child link in the event that a child is matched to different fathers in different years. Only non-imputed fathers and sons are retained. (The father may not be the biological father, but rather should be thought of as the male household head.) Sons are restricted to having been born between 1963 and 1966. Three classes of sons are excluded because the father-child link was not identified: those sons who did not file an income tax return between 1982 and 1986 while still at home; those who filed a tax return and were linked to a family that had no father; and those who filed a tax return but were not linked to a family.

Using these father-son pairs of SINs we obtain income information from the fathers' 1978 to 1982 T1 forms, and the sons' 1995 T1. We are able to link the 1995 T1 records of 497,242 sons to the T1 data of a father in at least one of the years from 1978 to 1982. Restricting this sample to include only the oldest sons in cases where multiple individuals were matched to the same father yields a sample size of 448,196 .

Our analysis is based upon two income measures: Earnings and Total Market Income. Earnings includes earnings taken from T4 slips as well as reported directly by tax filers. (T4s are issued by employers and must be remitted with the T1 form. Commissions earned by paid workers are included. In 1995 the minimum income for which a T4 must be issued was $\$ 500$ current dollars. Previously this was $\$ 250$, again in current dollars.) Earnings also includes "Other Employment Income," which is defined as the sum of adult training allowances, net research grants, tips and gratuities, royalties from a work or invention and director's fees. These are reported directly on the T1 by tax filers. (We compared the raw T4 data generated by employers to the earnings reported by individuals on the $\mathrm{T} 1$ and found that they matched up almost exactly. The exception to this was at the very bottom of the income distribution because of the minimum income determining whether a T4 is issued.) "Total Market Income" includes income from Earnings, Net Income from Self-Employment, Income from Assets, and Other Income. (Asset income has four components: [1] dividends from Canadian corporations; [2] net income from rental properties; [3] net capital gains or period losses; [4] income from interest and other investments). Some elements of Other Employment Income-royalties and directors fees in particular-do not reflect income from a employer-employee relationship and might be more correctly considered 
as a part of Market Income. However, we are not able to separate these elements and in total consider it more appropriate to add them to earnings. (This distinction, however, does not influence our results. The least squares estimates based upon a measure of Earnings net of Other Employment Income are the same as those using the sum of the two measures.) More detail on our definitions are available upon request. 
Figure A-1

\section{ALGORITHM USED IN THE CREATION OF THE FATHER-SON LINKS}

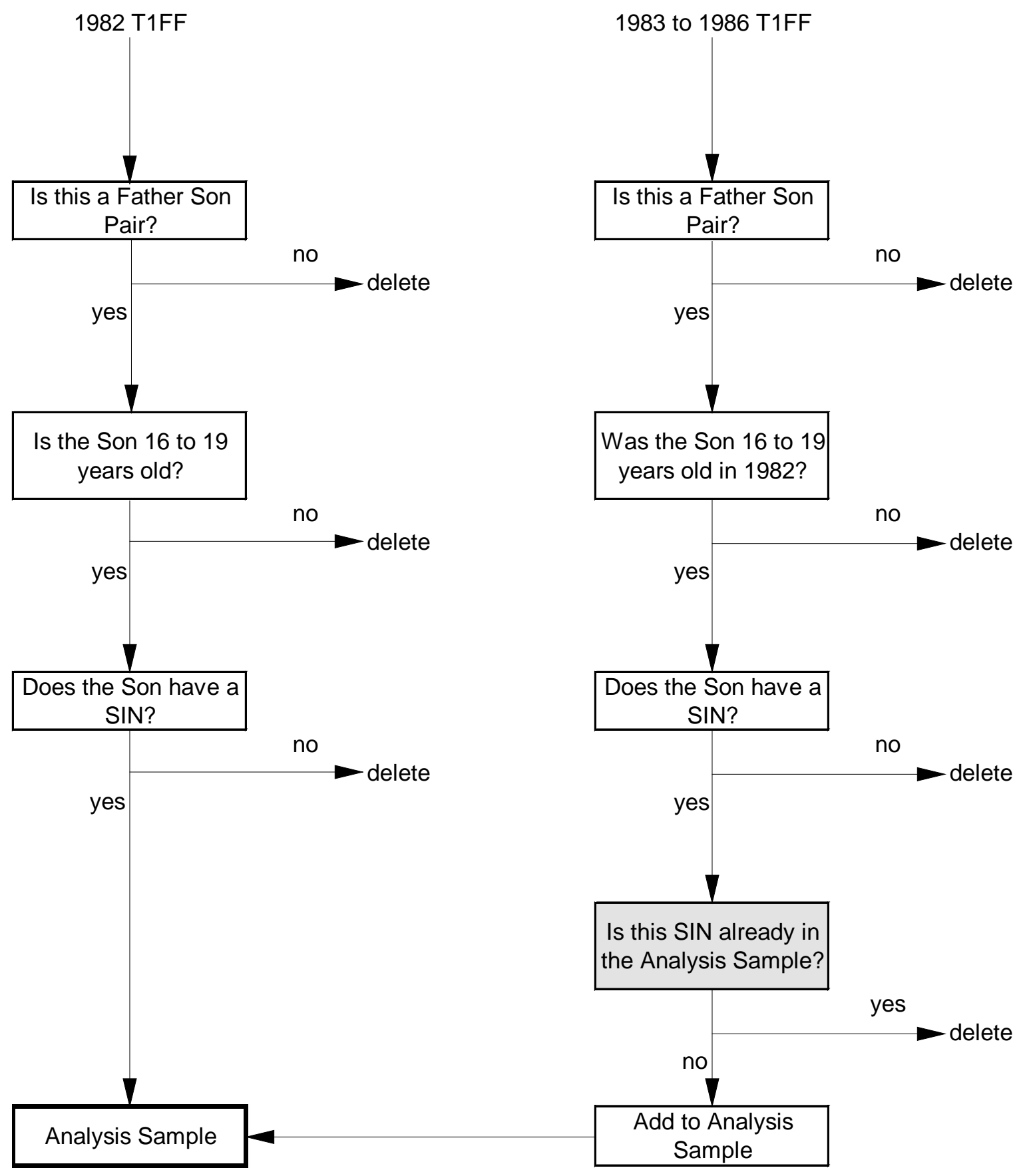




\section{Bibliography}

ALTMAN, N. S. (1992). "An Introduction to Kernel and Nearest-Neighbor Nonparametric Regression.” The American Statistician. Vol. 46, No. 3 (August), pp. 175-185.

ALTONJI, Joseph G. and Thomas A. Dunn (1991). "Relationships among the Family Incomes and Labor Market Outcomes of Relatives." Research in Labor Economics. Vol. 12, pp.269-310.

ATKINSON, Anthony B. (1981). "On Intergenerational Income Mobility in Britain.” Journal of Post Keynesian Economics. Vol. 3 (Winter), pp. 194-218.

A.K. Maynard, and C.G. Trinder (1983). Parents and Children: Incomes in Two Generations. London: Heinemann Educational Books.

BECKER, Gary S. (1991). A Treatise on the Family. Enlarged Edition. Cambridge Massachusetts: Harvard University Press.

and Nigel Tomes (1986). "Human Capital and the Rise and Fall of Families." Journal of Labor Economics. Vol. 4, No.3 pt.2, pp. S1-S39.

(1979). "An Equilibrium Theory of the Distribution of Income and Intergenerational Mobility.” Journal of Political Economy. Vol. 87, No. 6 pp. 1153-89.

BEHRMAN, Jere R. And Paul Taubman (1990). "The Intergenerational Correlation between Children's Adult Earnings and their Parents' Income: Results from the Michigan Panel Survey of Income Dynamics." Review of Income and Wealth. Series 36, No.2 (June), pp.115-27.

(1986). "Intergenerational Mobility in Earnings in the U.S.: Some Estimates and a Test of Becker's Intergenerational Endowments Model." Review of Economics and Statistics. Vol. 67, No. 1 (February), pp. 144-51.

BÉLAND, François (1987). “A Comparison of the Mobility Structure of Francophones and Anglophones in Quebec: 1954, 1964, 1974." Canadian Review of Sociology and Anthropology. Vol. 24, No. 2 pp. 232-251.

BÉNABOU, Roland (1994). "Human capital, inequality, and growth: A local perspective." European Economic Review. Vol. 38, pp. 817-26.

BOYD, Monica, John Goyder, Frank E. Jones, Hugh A. McRoberts, Peter C. Pineo, John Porter (1981). "Status Attainment in Canada: Findings of the Canadian Mobility Study." Canadian Review of Sociology and Anthropology. Vol. 18, No. 5 pp. 657-73.

BJÖRKLUND, A.A. and M. Jäntti (1997a). "Intergenerational Income Mobility in Sweden Compared to the United States." American Economic Review. Vol. 87, No. 5 (December), pp.1009-18. 
(1997b). "Intergenerational Mobility of Economic Status: Is the United States Different?" Paper presented to the AEA meetings, New Orleans.

BROOKS-GUNN, Jeanne, Greg J. Duncan, Pamela Kato Klebanov, Naomi Sealand (1993). "Do Neighborhoods Influence Child and Adolescent Development?" American Journal of Sociology. Vol. 99, No. 2 (September), pp. 353-95.

CARD, David and Richard B. Freeman (1993). "Introduction." In David Card and Richard B. Freeman (editors). Small Differences that Matter: Labor Markets and Income Maintenance in Canada and the United States. Chicago: University of Chicago Press.

CLARK, Collen (1997). "1995 Labour Force Income Profiles Reconciliation With Other Statistics Canada Data." Small Area and Administrative Data Division, Statistics Canada. Unpublished mimeo.

CLEVELAND, William S. and Susan J. Devlin (1988). "Locally Weighted Regression: An Approach to Regression Analysis by Local Fitting." Journal of the American Statistical Association. Vol. 83, No. 403, Applications and Case Studies. (September), pp. 596-610.

Susan J. Devlin, and Eric Grosse (1988). "Regression by Local Fitting: Methods, Properties, and Computational Algorithms." Journal of Econometrics. Vol. 37, Annals No. 1. (January), pp. 87-114.

(1993). Visualizing Data. Summit, New Jersey: Hobart Press.

and Clive Loader (1995). "Smoothing by Local Regression: Principles and Methods." Unpublished mimeo. AT\&T Bell Laboratories.

COOPER, Suzanne J., Steven N. Durlauf, and Paul A. Johnson (1993). "On the Evolution of Economic Status Across Generations." Paper presented to the Annual Meeting of the American Statistical Association, San Francisco California.

CORAK, Miles and Andrew Heisz (1998). "How to Get Ahead in Life: Some Correlates of Intergenerational Income Mobility in Canada." In Miles Corak (editor). Labour Markets, Social Institutions, and the Future of Canada's Children. Ottawa: Statistics Canada, Catalogue No. 89-553.

(1995). “The Intergenerational Income Mobility of Canadian Men.” Canadian Business Economics, Vol. 4, No. 1 (Fall), pp. 59-69.

CORCORAN, Mary, Roger Gordon, Deborah Laren, Gary Solon (1992). "The Association Between Men's Economic Status and Their Family and Community Origins." Journal of Human Resources. Vol. 27, No. 4 (Fall), pp. 575-601.

COUCH, Kenneth A. and Thomas A. Dunn (1997). "Intergenerational Correlations in Labor Market Status: A Comparison of the United States and Germany." Journal of Human Resources. Vol. 22, No.1 (Winter), pp. 210-32. 
COUCH, Kenneth A. and Dean R. Lillard (1997). "Sample Selection Rules and the Intergenerational Correlation of Earnings." Labour Economics. Forthcoming.

CREESE, Gillian, Neil Guppy, and Martin Meissner (1991). Ups and downs on the ladder of success: Social mobility in Canada. Statistics Canada, Catalogue No. 11-612E, No. 5.

DEARDEN, Lorraine, Stephen Machin, and Howard Reed (1997). "Intergenerational Mobility in Britain.” Economic Journal. Vol. 107, No. 1 (January), pp. 47-66.

DURLAUF, Steven N. (1996). “A Theory of Persistent Income Inequality.” Journal of Economic Growth. Vol. 1, No. 1 pp. 75-94.

(1994). "Spillovers, stratification, and inequality." European Economic Review. Vol. 38, pp. 836-845.

FORTIN, Nicole M. and Sophie Lefebvre (1998). "Intergenerational Income Mobility in Canada." In Miles Corak (editor). Labour Markets, Social Institutions, and the Future of Canada's Children. Ottawa: Statistics Canada, Catalogue No. 89-553.

FOURNIER, Élaine, George Butlin, and Philip Giles (1995). "Intergenerational change in the education of Canadians." In Dynamics of Labour and Income: 1994 Report. Statistics Canada, Catalogue No. 75-201E.

GOLDBERGER, Arthur S. (1989). "Economic and Mechanical Models of Intergenerational Transmission.” American Economic Review. Vol. 79, No. 3 (June), pp. 504-13.

GUSTAFSSON, Björn (1994). "The Degree and Pattern of Income Immobility in Sweden." Review of Income and Wealth. Series 40, No.1 (March), pp. 67-86.

HÄRDLE, Wolfgang (1990). Applied nonparametric regression. Cambridge U.K.: Cambridge University Press.

Verlag.

(1991). Smoothing Techniques With Implementation in S. New York: Springer-

HARRIS, Shelly and Daniela Lucaciu (1994). "An Overview of the T1FF Creation." LAD Reports, Reference Number 94-24-01 v1.2. Small Areas and Administrative Data Division, Statistics Canada.

HAVEMAN, Robert and Barbara Wolfe (1994). Succeeding Generations: On the Effects of Investments in Children. New York: Russell Sage Foundation.

HILL, Martha S. and Greg J. Duncan (1987). "Parental Family Income and the Socioeconomic Attainment of Children." Social Science Research. Vol. 16, pp. 39-73.

HUNGERFORD, Thomas L. (1993). "U.S. Income Mobility in the Seventies and Eighties." Review of Income and Wealth. Series 39, No.4 (December), pp. 403-17. 
ISAJIW, Wsevolod W., Aysan Sev'er, and Leo Driedger (1993). "Ethnic Identity and Social Mobility: A Test of the 'drawback model'. " Canadian Journal of Sociology. Vol. 18 No.2, pp. 177-96.

JENKINS, Stephen (1987). "Snapshots versus Movies: 'Lifecycle Biases' and the Estimation of Intergenerational Earnings Inheritance." European Economic Review. Vol. 31, pp. 114958.

LILLARD, Dean R. (1998). "Non-linearities in Intergenerational Mobility in Education and Earnings." Paper presented to the meetings of the American Economics Association, Chicago Illinois.

LILLARD, Lee A. and Robert T. Reville (1997). "Intergenerational Mobility in Earnings and Occupational Status." Paper presented to the meetings of the American Economics Association, Chicago Illinois.

McROBERTS, Hugh and Kevin Selbee (1981). "Trends in Occupational Mobility in Canada and the United States: A Comparison." American Sociological Review. Vol. 46 (August), pp. 406-21.

McROBERTS, Hugh (1980). "An Income Attainment Model for Native-Born Canadian Male Wage Earners." In Reflections on Canadian Incomes. Ottawa: Economic Council of Canada.

MICHAUD, Sylvie, David Dolson, Donna Adams, and Martin Renaud (1995). "Combining Administrative and Survey Data to Reduce Respondent Burden in Longitudinal Surveys." Statistics Canada, SLID Research Paper Series No. 95-19.

MITCHELL, Barbara A., Andrew V. Wister, and Thomas K. Burch (1989). "The Family Environment and Leaving the Parental Home." Journal of Marriage and the Family. Vol. 51 (August), 605-13.

MUlligAN, Casey B. (1997). Parental Priorities and Economic Inequality. Chicago: University of Chicago Press.

PETERS, Elizabeth H. (1992). "Patterns of Intergenerational Mobility in Income and Earnings." Review of Economics and Statistics. Vol. 74, No. 3 pp.456-66.

SHEA, John (1997). “Does Parents’ Money Matter?” NBER Working Paper No. 6026.

SOLON, Gary (1997). "Intergenerational Mobility in the Labor Market." Forthcoming in the Handbook of Labor Economics.

(1992) "Intergenerational Income Mobility in the United States." American Economic Review. Vol. 82, No.3 (June), pp. 393-408.

(1989). "Biases in the Estimation of Intergenerational Earnings Correlations." Review of Economics and Statistics .Vol. 71, No.1 (February), pp. 172-74. 
, Marianne E. Page and Greg J. Duncan (1997). "Correlations between Neighboring Children in Their Subsequent Educational Attainment." Unpublished mimeo.

WANNER, Richard A. and Bernadette C. Hayes (1996). "Intergenerational Occupational Mobility Among Men in Canada and Australia." Canadian Journal of Sociology. Vol. 21 No. 1, pp. 43-76.

ZIMMERMAN, David J. (1992). "Regression Toward Mediocrity in Economic Stature." American Economic Review. Vol. 82, No. 3 (June), pp. 409-29. 


\section{Endnotes}

$1 \quad$ The correlation coefficient between father and son $\log$ incomes $(\rho)$ is equal to $\beta_{1}$ if the degree of inequality (in the cross-sectional income distribution) does not change across generations, otherwise $\beta_{1}=\rho\left[\sigma\left(Y_{i}(t)\right) / \sigma\left(Y_{i}(t-1)\right)\right]$, where the $Y_{i}$ are measured in logarithms and $\sigma$ signifies the standard deviation of the variables in parentheses. Mulligan (1997, 164-70) points out that the changes in inequality over time depend upon the value of $\beta_{1}$.

$2 \quad$ For example, if the income levels in the above relationship are expressed as natural logarithms then $\beta_{1}$ represents the elasticity of a child's income with respect to the parental income. In Canada during 1981 the ratio of the average income of males (working full-year, full-time) in the top quintile to those in the bottom quintile was 3.84. Using this figure the income advantage conferred to someone born to a father with income in the top quintile relative to someone born to a father with income in the bottom quintile for different values of $\beta_{1}$ is as follows:

\begin{tabular}{l|lllll}
$\beta 1$ & 0.1 & 0.2 & 0.3 & 0.4 & 0.5 \\
\hline $\begin{array}{l}\text { Income } \\
\text { Advantage }\end{array}$ & $14 \%$ & $31 \%$ & $50 \%$ & $71 \%$ & $96 \%$
\end{tabular}

3 While numerous sociological studies exist, they deal with "social mobility," and are concerned with changes in occupational status of parents and children. Examples include McRoberts and Selbee (1981), Béland (1987), Isajiw, Sev'er, and Driedger (1993), Creese, Guppy, and Meissner (1991), Fournier, Butlin, Giles (1995), and Wanner and Hayes (1996). Boyd et.al. (1981) discuss the correlation between educational attainment and occupational status of fathers with sons and daughters stratified by ancestry and language. McRoberts (1980) relates these background characteristics to the incomes of sons in an analysis that is probably closest in spirit to those described in the text.

$4 \quad$ Haveman and Wolfe (1994) and Peters (1992) add a host of family background characteristics that are motivated by Becker's theory. Hill and Duncan (1987), Corcoran, Gordon, Laren, and Solon (1992), Brooks-Gunn, Duncan, Klebanov in ref., and Sealand (1993), Solon, Page and Duncan (1997) and Corak and Heisz (1998) also study the effects of family background as well as neighbourhood characteristics. Cooper, Durlauf and Johnson (1993) stratify their sample by neighbourhood in an attempt to uncover areas of permanent poverty or affluence. They find that families residing in affluent and poor neighbourhoods have higher income persistence than those in middle class families. However, they are forced to deal with a rather broad definition of neighbourhood and a rather small sample.

$5 \quad$ The "father" is not necessarily the biological father, but should rather be thought of as the male household head. Stepfathers, for example, will be included. To be included in the analysis the father must have been born between 1908 and 1952 inclusive.

$6 \quad$ We also derived a measure of earnings that includes earnings from paid employment and net self-employment income. The analysis of these data is available upon request.

$7 \quad$ It may be argued that our cohort of men is still too young and therefore that we are not measuring their permanent income accurately: at 29 to 32 years of age, some members of the sample may be just beginning to reap the benefits of extensive investments in human capital made during their twenties and will go on to move up in the income distribution. In fact, the age of this cohort is not out of line with that used in the existing U.S. literature, but we attempt a very rough assessment of this issue by examining the income dynamics over a ten year period of a group of men who were 29 to 32 years of age in 1985, that is in our age group but a decade earlier. About 24 percent of these individuals occupied the same decile in the income distribution in 1995 as they did in 1985, and about 55 percent were either in the same decile or one decile above or below. By way of comparison 27 percent of a group of men ten years older (39 to 42) in 1985 occupied the same income decile in 1995, and 59 percent were in the same or one decile above or below their 1985 decile. This suggests that the pattern of income dynamics is not too different for those in their late 20s and early 30 s as it is for a cohort in their late 30 s and early 40 s, that is for a cohort that may be considered to be well along the life-time income trajectory. 
When income is averaged the average age over the equivalent time interval is used.

9 The correlation coefficients associated with these elasticities, calculated in the manner described in note 1 are all uniformly less than 0.2 and not subject to as much variation. The correlation coefficients associated with row 1 of the table are 0.154 for earnings and 0.132 for income, and they range respectively from roughly 0.12 to 0.17 , and from 0.11 to 0.19 for the other scenarios.

10 Mitchell, Wister, and Burch (1989) find that the average age of final home leaving is about 20 years for those oldest children of biological parents, with men tending to leave home about nine months later than women. While this might be taken to suggest that under-representation in our data may not be too severe, it should be noted that their analysis refers to a wide spectrum of individuals leaving home during the 1950s through to the mid-1980s and may not be entirely comparable to the cohort we examine.

11 In the T1FF this issue of under-coverage is addressed by imputing children to certain families according to a rule based upon the age of the mother and her marital status. We do not use any imputed information. Clark (1997) offers a more detailed comparison between the SCF and T1 based administrative data, pointing out some of the conceptual and methodological differences between the two sources. She notes that the difference between the population and employment counts between them is due to the exclusion of non-filers from the tax data, and that in 1995 the average earnings of this group must have been about $\$ 1,500$.

12 Further, it is well known that income reported to surveys suffers from a rounding problem reflecting the fact that respondents have a "digit preference" and tend to report figures that are multiples of ten, a hundred, or one thousand. Rounding errors may be more important at the upper end of the income distribution. Almost 54 percent of SCF respondents report their earnings in a multiple of $\$ 100,46$ percent in a multiple of $\$ 1,000$, and 23 percent in a multiple of $\$ 10,000$. Only 12.6 percent of the oldest filers with fathers used a multiple of $\$ 100$, and 11.7 percent used a multiple of either $\$ 1,000$ or $\$ 10,000$. The differences between the two sources are even greater when market income is considered: 46 percent of SCF respondents report in multiples of $\$ 100$, but only 5.6 percent of oldest tax filers; 37 and 14 percent used respectively a multiple of $\$ 1,000$ and $\$ 10,000$, while 4.6 percent of filers did so.

13 We also conducted a similar analysis using the son's earnings as the regressand and the father's total market income as the regressor, obtaining a least squares estimate (and standard error) of 0.191 (0.009). The Heckman corrected estimate was 0.194 (0.009).

14 The sons' incomes are averaged over three years since transitory fluctuations may lead to an overstatement of mobility when depicted in a transition matrix, even if they don't bias the regression results. In fact, using income from only 1995 does not make a difference to the results. The data used are the residuals from the regression $Y_{i}=\gamma_{0}+\gamma_{1} A g e+$ $\gamma_{2} \mathrm{Age}^{2}$, where $i=$ father,son and $Y$ represents the level of income (expressed in constant 1986 dollars).

15 See Altman (1992) and Härdle $(1990,1991)$ for an introduction to non-parametric techniques. Our approach is based upon the work of Cleveland and Devlin (1988), Cleveland, Devlin, and Grosse (1988), Cleveland (1993, pp, 94101), and particularly Cleveland and Loader (1995). Our analysis uses the LOCFIT program written by Loader, which is available at http://cm.bell-labs.com/cm/ms/departments/sia/project/locfit/index.html.

16 The algorithm is actually more complicated than described and does not require as many regressions to be run as the number of observations. See Cleveland, Devlin and Grosse (1988) for details.

17 Specifically, if $u=Y_{i}(t-1)-Y_{o}(t-1)$, we desire a function that is peaked at $u=0$, decays smoothly to 0 as $u$ increases in absolute value, and is nonzero on a bounded interval. The tricubic weight function is: $w(u)= \begin{cases}\left(1-|u|^{3}\right)^{3} & |u|<1 \\ 0 & |u|>1\end{cases}$

18 The references cited in footnote 15 , particularly those by Cleveland and his co-authors point out that choosing $\alpha$ in a mechanical way by relying upon an indicator like the AIC will often lead to incorrect choices. The choice of $\alpha$ should not be made without reference to the objectives of the analysis. Further, as Härdle (1990) points out, minimizing such a criterion with respect to the choice of the smooth does not necessarily lead to an optimal choice for the first 
derivative of the smooth. For these reasons we use the AIC as a guide, but only as a guide, to the choice of $\alpha$. An often used rule of thumb is to adopt a value of 0.7 .

19 The sample is determined by choosing all those sons whose Social Insurance Number ended with the digit 5 subject to their earnings or income being greater than or equal to one, and subject to the five year average of the corresponding measure for the father also being greater than or equal to one.

20 We looked more closely at these outliers and found that while earnings were very low many of these individuals had higher total incomes (total market income including government transfers). There was a group on the margins of the labour market receiving Unemployment Insurance benefits and Social Assistance. Others were receiving Workmen's Compensation or were living off grants, fellowships, or other benefits, indicating (in some cases) continued participation in post-secondary education. Some of the fathers also reported Canada/Quebec Pension Plan income. Using a cut-off of -8 does not change the findings.

${ }^{21}$ Other values of $\alpha$ were also explored. A value of 0.7 does not lead to very different results, except possibly at the upper tail where the elasticity reaches 0.5 as opposed to being just under 0.4 when $\alpha$ is set to 0.84 . A value of 0.9 appears to oversmooth the data, eliminating the increase in the elasticity at log age-adjusted earnings above two. 